\title{
New technology assessment in entrepreneurial financing - Does crowdfunding predict venture capital investments?
}

\author{
Jermain Kaminski $^{\mathrm{a}}$, Christian Hopp ${ }^{\mathrm{a}, *}$, Tereza Tykvová ${ }^{\mathrm{b}}$ \\ ${ }^{\mathrm{a}}$ RWTH Aachen University, TIME Research Area, Kackertstraße 7, 52072 Aachen, Germany \\ ${ }^{\mathrm{b}}$ Hohenheim University, Wollgrasweg 49, 70599 Stuttgart, Germany
}

\section{A R T I C L E I N F O}

\section{Keywords:}

Technology prediction

Granger causality

Reward-based crowdfunding

Venture capital

\begin{abstract}
A B S T R A C T
Crowdfunding is a relatively new gateway for entrepreneurs to access capital for creative and innovative ideas. It allows individuals to start experiments with new products and technologies where the outcome is distant. Yet predicting the success of hitherto unseen products and technologies is fraught with ambiguity and uncertainty. Early stage product experimentation and market access through reward-based crowdfunding, where potential customers provide funds for new unproven products, can therefore provide quality signals to subsequent financiers of new technologies. Our study investigates whether there is a long-run relationship between crowdfunding and VC investments on the aggregate and the industry level. We draw on a dataset covering 77,654 projects that successfully raised funds on Kickstarter and 3260 VC investments in the US between 2012 and 2017. The results suggest that crowdfunding Granger causes VC investments. Moreover, the monthly crowdfunding and VC investment time series are cointegrated. We therefore conclude that successful crowdfunding campaigns lead to a subsequent increase in VC investments. This holds at the aggregate level and particularly for hardware and consumer electronics, as well as fashion. These results enhance our understanding of the codevelopment between crowdfunding and VC investments. Reward-based crowdfunding helps VC investors in assessing future trends rather than crowding them out of the market.
\end{abstract}

\section{Introduction}

Predicting the success of new technologies or business models is plagued with tremendous uncertainty. For novice or nascent firms and unproven technologies, it is difficult to forecast whether the revenue model will work and whether the technology will be feasible. Apparently, the probability that such endeavours succeed is low, extremely skewed, and difficult to predict (Kerr et al., 2014a).

In a Canadian sample, Åstebro (2003) finds that only 7-9\% of entrepreneurs succeed in turning their inventions into marketable products. Related to this, for venture capital (VC) investors, it is difficult to assess which technology or venture will succeed or which industry offers a high potential (Ewens and Rhodes-Kropf, 2015). Kerr et al. (2014b) report on large prediction errors by VC investors about potential projects and observe low correlations between investors' assessments and levels of future success. They describe in detail the hesitations of investors to fund Airbnb because they could simply not understand (or imagine) that the business model could actually work. Passing on what later turns out to be extremely successful endeavours are not an exception.
Along these lines, crowdfunding is a relatively new gateway for entrepreneurs to access capital for creative and innovative ideas, let that be for novel and de novo products or products already close to market commercialization (Belleflamme et al., 2014; Cumming and Johan, 2017; Mollick, 2014; Schwienbacher and Larralde, 2012). It allows individuals to start experiments with new products and services within a wide range of capital supply, where the outcome is distant, as was the case for the Oculus Rift, or allow founders to scale up their operations for products already developed. The amount may vary from a few dollars for a pottery project to $\$ 20$ million for a new smart watch. Crowdfunding has evolved over the years from experimental products to Kickstarter now explicitly recommending funders to show potential backers a prototype of the technology or product.

Given the difficulty of VC investors to predict and assess new technologies and the surge of new platforms to fund early stage entrepreneurial experimentation (Kollmann and Kuckertz, 2010), the aim of this paper is to investigate whether there is a positive long-run relationship between crowdfunding and venture capital (VC) investments, in which VC investments follow crowdfunding investments at a time lag. Hence, a positive early assessment of the crowd for technology

\footnotetext{
* Corresponding author.

E-mail addresses: kaminski@time.rwth-aachen.de (J. Kaminski), hopp@time.rwth-aachen.de (C. Hopp), tereza.tykvova@uni-hohenheim.de (T. Tykvová).
} 
segments and industries may provide a signal for VC investors in which direction technological evolutions and commercialization might be heading. As Cheng et al. (2017:1) have put it: "[...] it is only by periodically scanning the technological horizons can a firm become aware of potentially disruptive technologies." Just like bees may indicate the direction to a distant flower patch yielding nectar and pollen through a "waggle dance" in their hive (Von Frisch, 1967), crowdfunding investors may complement the activities of VC investors, by providing them with information towards new products and product categories.

Although crowdfunding may be an important predictor of VC investment activity, surprisingly we know little about how the opportunity for entrepreneurial experimentation through crowdfunding affects the demand for VC investments and the amount that VC investors eventually provide. If the quality and number of entrepreneurs vary across time, then so does the opportunity for VC investors to fund investments. Our research questions ask whether there is a long-run relationship between crowdfunding and VC investments on the aggregate and the industry levels, and whether an increase in crowdfunding causes an increase in VC investments. To answer these questions, we use a dataset covering 77,654 crowdfunding investments that have successfully reached their funding goal and $3260 \mathrm{VC}$ investments in the US. Our analysis starts in April 2012, and ends in March 2017. The results suggest that crowdfunding Granger causes VC investments. We also find a long-term relationship between crowdfunding and VC investments; the time series are cointegrated. Successful crowdfunding campaigns lead to a subsequent increase in VC investments. This holds in aggregate and especially for hardware and consumer electronics, as well as fashion. Overall, we believe that our results further enhance our understanding of the co-development between VC investments and reward-based crowdfunding. We draw a picture of a nuanced financing eco-system in which entrepreneurial cycles and investment cycles are intertwined.

\section{Related literature and research question}

\subsection{Crowdfunding background}

This work deals with crowdfunding, which has been playing an increasing role in financing entrepreneurial companies. Entrepreneurs raise funds via online platforms, such as Kickstarter, that also provide entrepreneurs with a direct interaction with potential end users. Through their feedback, end users provide evaluations of the business idea and may prove useful in reshaping and improving the product. Crowdfunding can help to aggregate market expectations about future trends and technologies (Cumming et al., 2015). The entrepreneurs not only attract potential customers and early-stage financiers on the crowdfunding platform, but also obtain higher visibility (e.g., through press coverage). Mollick and Kuppuswamy (2014) suggest that crowdfunding appears to support traditional entrepreneurship. The visible large-scale involvement of the online brand community may present a strong signal of a projects viability and market validity, which in turn may influence the perception of other investors that have not invested yet (Agrawal et al., 2015; Lehner et al., 2015). Not surprisingly, crowdfunding has been influential in areas such as gaming, internet related technologies, wearable computing, music, and three-dimensional printing (Gamble et al., 2017; Mollick and Nanda, 2015), which directly addresses end users. Mollick and Kuppuswamy (2014) conduct a follow-up survey of Kickstarter projects and find out that crowdfunding helps not only in drawing interest from other investors, but also attracts customers and employees. By offering a direct market test, crowdfunding provides information about customer adoption and market size and makes product demand easier to calculate (Chemla and Tinn, 2016). Moreover, successful entrepreneurs and projects generate spillovers and spur the evolvement of new technology fields. Further companies emerge and grow (Agrawal et al., 2015; Cumming and Johan, 2017). In crowdfunding, numerous small investors place bets on the potential of a business idea. VC usually invests in firms that go beyond the mere innovative idea and generally place industry and sectors bets. Though, theoretically treated as being distinct sources of funds, we suggest in this paper that the two might be inherently linked and part of a synergistic financing eco-system.

In a broader sense, on the one hand crowdfunding extends financing possibilities for companies and on the other investment opportunities for individuals. Thus, crowdfunding is not a stand-alone phenomenon, but it carries implications for capital markets. In this paper, our prior is that the crowd may perform an expert-like assessment of future technology trends. Through this assessment, it may provide VC investors with a crowd-driven proof of concept for new technologies and markets.

Crowdfunding platforms may therefore nurture products and ideas, which otherwise might not be pursued. The "wisdom of the crowd" may not only lead to more projects that search for VC financing, but also improve the quality of projects that compete in the marketplace. This is important as deal flow has been shown as a large concern for VC investors (Hochberg et al., 2010), in particular in hot periods when "too much money chases too few deals" (Gompers and Lerner, 2000). Crowdfunded projects might generate spillovers spurring the birth and development of further companies in the same and related technology fields as successful crowdfunding campaigns may raise the interest in new projects and co-creations.

\subsection{Technology assessment and venture capital financing}

The availability of financial capital is recognized as having a significant impact on whether entrepreneurs are able to progress in the gestation stage of new venture creation, or whether they have to abandon their business idea (Holtz-Eakin et al., 1994; Reynolds, 2011; Van Gelderen et al., 2006). Entrepreneurs and their financiers face the uncertainty about whether or not a particular product or a business model will turn out to be successful. Various types of new ventures' financiers deal with these uncertainties in different ways.

For outsiders, it is impossible to gauge the quality of an entrepreneur's characteristics and actions, and especially to understand the potential of radical innovation and technologies (Plummer et al., 2016). For VC investors, it is difficult to assess which technology or venture will succeed or which industry offers a high potential (Ewens and Rhodes-Kropf, 2015). Consequently, substantial residual uncertainty about venture viability exists. Kerr et al. (2014a) argue that the highly skewed returns of VC investors are evidence in favor of high uncertainty and large prediction errors. When VC investors decide in which companies and industries to invest, they consider different criteria. Kaplan and Strömberg (2004) distinguish between three categories: internal factors (such as management quality), external factors (such as market size and customer adoption) and difficulty of execution and implementation. While internal factors are subject to asymmetric information between the entrepreneur and the VC investor, external factors are subject to uncertainty. However, the information is not necessarily asymmetrically distributed because entrepreneurs may face the uncertainty as well. VC investors often reward stock options to founders that secure threshold number of customers who have purchased the product and reported positive feedback (Kaplan and Strömberg, 2004). This contingency supports the view that external factors, such as the expected market size and customer adoption, are important for VC investors. This is understandable, since such factors directly affect project revenues.

\subsection{Technology assessment and crowdfunding}

Crowdfunding may reveal information about these external factors. The process offers multiple evaluations by thousands of potential backers, who as end users of the product might be well positioned to judge the project's viability. Through their investments, individual backers express their interest in using the product and their belief in its 
successful development. Products are therefore not developed on the perceptions and wishes of imaginary customers. Instead, they evolve if and only if real customers buy into their vision today.

Aggregated group decisions tend to be more accurate than decisions by individuals in which only a single decision maker relies on his sole assessment (Budescu and Chen, 2014). Recent research further attests to the role of third parties to improve signal quality (Plummer et al., 2016). Crowdfunding not only reflects an investment into future products, i.e., needs that may not satisfied in the current market, but also provides a crowd-driven proof of concept for certain technologies and markets. Crowdfunding may validate the authenticity of a firm and its technology, and may reduce uncertainty as to the feasibility and viability of new technologies. A wider range of expertise makes evaluation more accurate and reduces information frictions, providing greater efficiency in funding decisions. Recent empirical evidence supports the view that, despite the potential for herding and madness, the crowd makes accurate, expert-like assessments (Mollick and Nanda, 2015), and relies on signals (Ahlers et al., 2015; Mollick, 2013). Mollick and Kuppuswamy (2014) demonstrate a large success probability among projects funded via Kickstarter. Over $90 \%$ of funded projects remained ongoing ventures 1-4 years after their campaign. The (visible and oftentimes large-scale) involvement of the online brand community may present a strong signal of a project viability and market validity, which could strongly influence the perception of other investors who have not invested yet. Our study extends previous analyses that suggest that crowdfunding is able to lead to and support traditional entrepreneurship (Mollick and Kuppuswamy, 2014).

Hence, a successful crowdfunding campaign may act as an important marketing tool for newly created products or services, which obtain media attention. As such, it signals valuable information that attests the quality of the underlying business to potential new customers and investors. Therefore, on aggregate we hypothesize that the aggregate contribution to crowdfunding helps to predict the volume of aggregate venture capital investments.

\subsection{Crowdfunding and venture capital financing}

VC investors play an important role in selecting, financing and nurturing promising but uncertain ventures. To receive VC funding, business ideas undergo a profound screening process through a specialized individual investor. While information generation for the individual investor is expensive and cumbersome to obtain, observing several experiments and their reception by the market is valuable and may help to update prior beliefs.

At the company level, several studies support the view that crowdfunding facilitates VC financing. In a theoretical model, Chemla and Tinn (2016) explain how the crowdfunding process generates information that mitigates the risk of adverse selection and moral hazard for external investors. Drover et al. (2017a, 2017b) similarly conclude that crowdfunded investments certify venture quality and influence VC screening decisions. Crowdfunding seems to resolve demand uncertainty about new products and generate information on an entrepreneurs' ability to manufacture and deliver the proposed product. On a regional level, Sorenson et al. (2016) conduct an analysis of the number of crowdfunding investments and the number of subsequent venture capital investments, suggesting that a larger number of successful crowdfunding campaigns may cause a larger number of VC investments. Consistently, Colombo and Shafi (2016), Kuppuswamy and Roth (2016) as well as Ryu and Kim (2016) find that successful rewardbased crowdfunding campaigns increase the likelihood of obtaining external VC financing. Bandwagon effects have been reported (Mollick, 2013), where additional investors come on board when momentum is building up.

We expect that these mechanisms carry market wide implications. VC investors are uncertain about the success of a single specific company, but also about the success of a specific technology or industry.
Crowdfunding may provide information on future markets trends (and potential market sizes) as successful experiments shift the probability predictions of uncertain technologies. VC investors may observe aggregate crowdfunding behavior and process information on new trends to make more informed investment choices. When VC investors observe that a certain new technology received widespread community support, they may interpret it as an indicator of the technological feasibility in this field. According to Zider (1998: 131), "One myth is that venture capitalists invest in good people and good ideas. The reality is that they invest in good industries". Crowdfunding may give birth to further entrepreneurial projects as successful crowdfunding campaigns create interest in new projects and co-creations. Consequently, the deal flow for VC investors may increase exponentially. Take for example the market for smart locks. While Lockitron raised around $\$ 2$ million directly from their customers, the Yves Behar start-up August raised the same amount from Cowboy Ventures (and syndicate partners) and entered the market a few months later. Both companies represent bets on a potential standard that might emerge. The VC investors placed their bet after witnessing the early success of the first mover, and scaled their venture faster.

\section{Data}

We draw our sample from the crowdfunding platform Kickstarter and from the entrepreneurial financing database CrunchBase. As explained below, we believe that these two data sources are representative of crowdfunding and VC investment activity in US-based companies within the selected time window.

Our analysis considers crowdfunding and VC investments in the period from April 2012 to March 2017 and thus convers five full calendar years. We choose April 2012 as a starting date for two reasons: First, it was not until this date that the monthly volume of investments through Kickstarter considered in our analysis first exceeded \$10 million. Secondly, the point marks a structural break in the time series of investments from 2009 onwards (we depicted the graph of the monthly campaign contribution development in Table A.1 in the Appendix). Considering lower investment amounts and a higher sparsity (lower density) of data prior to 2012, we decided not to consider this timeframe in order to avoid spurious correlations. ${ }^{2}$

Kickstarter is a global crowdfunding platform, having the mission to "help bring creative projects to life". ${ }^{3}$ Kickstarter serves as an intermediary between potential funders and creators of projects, and does not claim any ownership over the projects. Individual funders (backers) can contribute small amounts of money starting from a few dollars. For their contributions, they are offered rewards, which vary depending on the amount the backer contributes. They can include small items such as cards, t-shirts or cups or events such as the possibility to spend a day with the project creator. Alternatively, the contributor can be one of the first that obtain the new product. Potential and actual project backers may participate in online discussions and exchange their opinions about

\footnotetext{
${ }^{1}$ http://www.hackthings.com/who-will-win-the-smart-lock-race-august-orlockitron/; accessed October 20th, 2017.

${ }^{2}$ The Jumpstart Our Business Startups (JOBS) Act enactment in April 2012 may have been an indirect trigger event for the steep rise investments in March 2012 even if its legislation addressed the regulation of equity crowdfunding, not reward-based crowdfunding. Until the passage of the JOBS Act, the use of internet funding portals in private placements was limited by law. We observe that investment volumes on Kickstarter sharply increased after the JOBS Act enactment, even though the SEC's regulations, known as Regulation Crowdfunding, became not effective before May 16, 2016 (cf. Bradford, 2018). As such, awareness for reward-based crowdfunding might have been in the slipstream of equity crowdfunding ever since the introduction of the JOBS act. We are thankful to an anonymous reviewer for clarifications and suggestions along these lines.

${ }^{3}$ https://www.kickstarter.com/charter; accessed October 20th, 2017.
} 
the project with the creator and among each other. Creators of projects apply for funding in fifteen different areas ranging from culture to technology. When they post a project, they choose a deadline and a minimum funding goal. Kickstarter operates on All-or-Nothing basis, meaning that only when the funding goal is reached the project creator will receive the pledged funds (Cumming, Leboeuf, and Schwienbacher, 2015). If the goal is not reached by the deadline, the project ends without any funds collected.

We gather information on all projects based in the US that successfully reached their funding goal within the period from 04/2012 to 03/2017 on the Kickstarter platform using a custom build webcrawler. The crawler collected and structured publicly available HTML and JSON code information from the Kickstarter website and its different project categories. Our crowdfunding segment comprises 77,654 projects and a total funding volume of $\$ 1.85$ billion (see Table 2) pledged by $21,904,867$ backers. A median project raised $\$ 5421$. The average pledge amount of $\$ 23,881$ is attributable to a few large projects. We extend prior research by focussing on the dollar amount raised, rather than simply studying the number of investments. In doing so, our empirical analysis is able to capture the magnitude of a potential effect in more detail by analysing the absolute (or log-transformed) investment amounts and conducting the analysis on monthly levels to infer causality.

We employ Kickstarter for three main reasons. Firstly, Kickstarter is the world's largest online crowdfunding platform, having raised more than $\$ 3.3$ billion from its inception on April 28, 2009 to October 20, 2017. Secondly, Kickstarter has been described as being representative of projects seeking funding from the crowd (Mollick, 2014 and 2016; Mollick and Nanda, 2015). Recently, several other researchers have started to use Kickstarter data (see for example Kuppuswamy and Roth, 2016; Li and Martin, 2016; among others). Thirdly, Kickstarter campaigns are associated with a strong backer network and active online communication between (potential) end users, which result in substantial information generation and transmission.

We perform analyses on the aggregate level (our aggregate crowdfunding measure includes all 15 categories available on Kickstarter) and additionally, we focus separately on the following investment categories: hardware and consumer electronics (which we label hardware), media, arts and entertainment (media), and fashion, wellness and personal care (fashion). ${ }^{4}$ We are able to assign $94.4 \%$ of all Kickstarter projects to one of these three categories. ${ }^{5}$

Our second data source, CrunchBase, ${ }^{6}$ is a database that comprises data on investments in entrepreneurial companies in the US (Cumming et al., 2016). Every registered member can make submissions to the database; however, all changes are subject to review by a moderator before being accepted. Analogously to the crowdfunding sample, we extract data for investments in US-based companies during the period spanning from $04 / 2012$ to $03 / 2017$. The VC segment consists of 3260 VC investments totalling $\$ 16.11$ billion (see Table 2). We retrieved the sample on September 15, 2017 for the CrunchBase subsegments angel, seed, and venture. Due to a low number of observations in the angel subsegment, we merged observations from the first two subsegments into one: angel_seed. We label the second subsegment early_growth, as it includes both these stages of VC financing. This fine-grained categorization also allows to study potential crowding-out effects in the

\footnotetext{
${ }^{4}$ Mollick (2014) defines seven basic themes based on the 15 Kickstarter categories: namely (i) art and craft, (ii) design, (iii) music, dance and theater, (iv) fashion, (v) film, video, and games, (vi) publishing, photography, comics, and journalism, and (vii) technology.

${ }^{5}$ The only Kickstarter category that we do not assign to one of the subsequently analyzed causality and cointegration pairs is "food", because the time series yields several zero entries, which would make the empirical analysis too fragile. Nevertheless, in order to consider a maximum of crowdfunding data, we include data for "food" into our "cf_sum" and "vc_sum" time series.

${ }^{6}$ https://data.crunchbase.com/.
}

lower VC investment range. While prior work uses aggregate VC investments, we differentiate between "Angel and Seed" as well as "Early and Growth" capital, in order to draw more precise conclusions concerning different investment stages (Sorenson et al., 2016). Lastly, we trimmed the sample to comprise only the $99 \%$ percentile to avoid size distortions by extreme outliers. We describe the investment segments, subsegments and categories in Table 1.

Within the CrunchBase dataset, we find a vast number of investments that do not correspond to similar categories on Kickstarter. We eliminate categories such as biotechnology, software, e-commerce and enterprise software development, clean technology and manufacturing, health care and life science, advertising, and semiconductors from the CrunchBase sample. ${ }^{7}$ The remaining 1282 CrunchBase categories represent a map with the three investment categories we defined for Kickstarter projects (compelling 170 categories on Kickstarter). The details on the mapping process can be obtained from the authors.

We are confident that CrunchBase is representative of the VC investment activity in US-based companies and has a wider coverage than competing databases. First, CrunchBase quarterly time series correlate highly with the National Venture Capital Association (NVCA) quarterly time series (Pearson correlation coefficient of 0.67) and cover almost $97 \%$ of the volume reported by the NVCA (Block and Sandner, 2009). ${ }^{8}$ To assess the representativeness of investment categories, we make a comparison between CrunchBase and other data sources, commonly used in VC research. Compared to Thomson and Venture Source, CrunchBase has a better coverage of small investments. Similarly, Alexy et al. (2012) attest to the wide spectrum covered in CrunchBase, ranging from very small to very large companies such as Google and Facebook.

\section{Methodology}

We perform our analysis in four steps. First, we begin with a test for the order of integration of all our time series, which subsequently affects our choice of methods. We employ the augmented Dickey-Fuller (ADF), Phillips-Perron (PP) and non-parametric Kwiatkowski-Phillips-Schmidt-Shin (KPSS) tests (Dickey and Fuller, 1979 and 1981; Kwiatkowski et al., 1992; Phillips and Perron, 1988). Several authors argue that joint testing can strengthen inferences made about the stationarity or non-stationarity of time series (e.g., Maddala and Kim, 1998). ${ }^{9}$

Second, we focus on Granger causality between crowdfunding and VC investments. In fact, robust inferences following Granger (1969) are only possible with stationary time series. Granger and Newbold (1974) as well as Phillips (1986) point out that Granger causality tests of nonstationary or mixed-stationary time series might suggest a statistically significant relationship where there is none: i.e., a spurious regression. As some of our time series turn out to be non-stationary, we resort to the robust procedure for integrated or cointegrated time-series

\footnotetext{
${ }^{7}$ While the CrunchBase dataset comprises many software investments, Kickstarter does not provide an equivalent category. We do not focus on software as a separate category because the use of CrunchBase software investments and Kickstarter software investments would imply an analysis of highly disproportionate data.

Most of the projects we manually controll for turn out as mainly hardware related projects with a software component. The Kickstarter category "games" which may indeed include "software" type of apps, is mapped to our category "media and entertainment", as the described software shows entertainment character.

${ }^{8}$ We cannot use data from the NVCA for our purposes, because they do not provide monthly time series for investment categories.

${ }^{9}$ The ADF and PP unit root tests test the null hypothesis that a time series $\mathrm{Y}_{t}$ is $I(1)$, while the KPPS stationarity test is a complementary test for the null hypothesis that $\mathrm{Y}_{t}$ is $I(0)$. ADF and PP tests can fail to reject the null hypothesis of a unit root (e.g., Davidson and MacKinnon, 2004).
} 
Table 1

Investment segments, subsegments and categories.

\begin{tabular}{|c|c|}
\hline Variable & Description \\
\hline \multicolumn{2}{|c|}{ Investment segments and subsegments } \\
\hline cf_sum & Volume (in \$) of Kickstarter crowdfunding investments. \\
\hline vc_sum & Volume (in \$) of CrunchBase venture capital investments (angel, seed, venture). \\
\hline vc_angel_seed & Volume (in \$) of venture capital investments attributable to angel investor and seed stage financing, denoted as "Angel" and "Seed" at CrunchBase. \\
\hline vc_early_growth & Volume (in \$) of venture capital investments attributable to venture (early stage and growth) financing, denoted as "Venture" at CrunchBase. \\
\hline \multicolumn{2}{|c|}{ Investment categories } \\
\hline cf_hardware & Volume (in \$) of crowdfunding investments in the investment category hardware and consumer electronics. \\
\hline cf_media & Volume (in \$) of crowdfunding investments in the investment category media, arts, entertainment. \\
\hline cf_fashion & Volume (in \$) of crowdfunding investments in the investment category fashion, wellness, personal care. \\
\hline vc_hardware & Volume (in \$) of venture capital investments in the investment category hardware and consumer electronics (hardware). \\
\hline vc_media & Volume (in \$) of venture capital investments in the investment category media, arts, entertainment (media). \\
\hline vc_fashion & Volume (in \$) of venture capital investments in the investment category fashion, wellness, personal care (fashion). \\
\hline
\end{tabular}

proposed by Toda and Yamamoto (1995), which we describe below. We complement, third, the findings using a visualization through impulse response functions (cf. Backus, 1986; Lütkepohl, 1990). Impulse response functions trace the response of current and future values of one endogenous variable to a one-unit increase of the exogenous variable (Cholesky decomposition). This differs from prior work that relied on time-series data, but inferred causality using fixed effects estimations on the two time-series and reported cross-sectional correlations among VC and crowdfunding investments in regions only (Sorenson et al., 2016).

Fourth, in order to detect common stochastic trends among the analyzed time series pairs, and in order to consider supporting results for the Toda-Yamamoto test, we perform the Johansen cointegration test (Johansen, 1988; Johansen and Juselius, 1990). If two variables share a common stochastic trend, there must be Granger causality in one or more directions between them (Cuthbertson et al., 1992). We test for the order of cointegration among our bivariate time series for investment segments, subsegments, and categories. The Johansen cointegration test makes the basic assumption that two $I(1)$ time series are cointegrated when their linear combination becomes an $I(0)$ process (cf. Engle and Granger, 1987; Johansen, 1988). Unlike Granger causality test, cointegration tests cannot establish the direction of causality, but identify cointegrating VARs, i.e., long-run equilibrium relationships. Foreshadowing some results here, in our subsequent analysis, we will find that some bivariate models may have mixed orders of integration, i.e. are $I(0)$ and $I(1)$. Therefore, and in view of inconclusive evidence regarding the stationarity of our time series, we decided to report cointegration results for variables of potentially different order of integration. $^{10}$

\subsection{Granger causality}

Wiener (1956: 127) introduces the notion that "for two simultaneously measured signals, if we can predict the first signal better by using the past information from the second one than by using the information without it, then we call the second signal causal to the first one". Granger (1969) follows this idea of causality in the context of linear autoregressive models of stochastic processes. A bivariate linear autoregressive model of two stationary time series $\mathrm{X}_{t}$ and $\mathrm{Y}_{t}$ with zero means can be written as following vector autoregressions (Granger,

\footnotetext{
${ }^{10}$ This also follows Lütkepohl \& Krätzig (2004, p.89) who write that: "Occasionally it is convenient to consider systems with both $I(1)$ and $I(0)$ variables. Thereby the concept of cointegration is extended by calling any linear combination that is $I(0)$ a cointegration relation, although this terminology is not in the spirit of the original definition because it can happen that a linear combination of $I(O)$ variables is called a cointegration relation".
}

1969; Giles, 1997):

$\mathrm{X}_{t}=\alpha_{1}+\sum_{i=1}^{p} \beta_{i} \mathrm{X}_{t-i}+\sum_{i=1}^{p} \gamma_{i} \mathrm{Y}_{t-i}+\varepsilon_{1 t}$

$\mathrm{Y}_{t}=\alpha_{2}+\sum_{i=1}^{p} \delta_{i} \mathrm{X}_{t-i}+\sum_{i=1}^{p} \varphi_{i} \mathrm{Y}_{t-i}+\varepsilon_{2 t}$

where $p$ is the maximum number of lagged observations included (the model order), vectors $\beta, \gamma, \delta, \varphi$ contain the coefficients of the model (contributions of each lagged observation to the predicted values of $\mathrm{X}_{t}$ and $\mathrm{Y}_{t}$ ), and $\varepsilon_{1 t}$ and $\varepsilon_{2 t}$ are uncorrelated white-noise series with meanzero sequence. If the variance of $\varepsilon_{1 t}$ (or $\varepsilon_{2 t}$ ) is reduced by the inclusion of lags of $Y_{t}\left(\right.$ or $X_{t}$ ), then $Y$ (or $\left.X\right)$ Granger causes $X$ (or $Y$ ). ${ }^{11}$ This implies that $Y$ is causing $X$, provided the coefficients in $\gamma_{i}$ are not zero. The interdependence can be tested by performing an F-test of the null hypothesis that $\gamma_{i}=0$, given assumptions of covariance stationarity on $X_{t}$ and $Y_{t}$ (Geweke, 1982). Similarly, $X$ is causing $Y$ if the coefficients in $\delta_{i}$ are not zero. If both of these events occur, there is said to be a "feedback" between $X$ and $Y$.

Yet Granger causality is highly dependent on the order of integration and the estimation of the VAR when its variables are integrated. Granger (1969) assumes that only stationary time series are involved. As our results indicate ambiguity as to the order of integration and cointegration properties, we follow the procedures suggested in Toda and Yamamoto (1995).

\subsection{Toda-Yamamoto Granger causality}

Toda and Yamamoto (1995) propose a simple but robust procedure irrespective of the system's integration or cointegration properties. This procedure requires the estimation of an augmented VAR which guarantees the asymptotic distribution of the Wald statistic (an asymptotic $\chi^{2}$-distribution), since the testing procedure is robust to the integration and cointegration properties of the process (Dolado and Lütkepohl, 1996). The Toda and Yamamoto (1995) test is a modified Wald (MWald) test for linear restrictions on some parameters of an

\footnotetext{
${ }^{11}$ Granger (1969) formalizes his theory of causality under the condition of two main axioms: (1) Causes precede their effects in time and (2) a time series $X_{t}$ causes a time series $Y_{t}$, if the prediction of the future of the time series $Y_{t}$ can be improved using the combined past values of $X_{t}$ and $Y_{t}$ rather than using information from the past of $Y_{t}$ alone. Formally, $Y$ is (Granger) causing $X$, when $\sigma^{2}(\mathrm{X} \mid \mathrm{U})>\sigma^{2}(\mathrm{X} \mid U-Y)$, where $\sigma^{2}(X \mid U)$ is the prediction error in the case where all information from the past is used, and $\sigma^{2}\left(X \mid U_{-}^{-} Y\right)$ is the prediction error corresponding to the situation when $Y_{t}$ was excluded from the information set.
} 

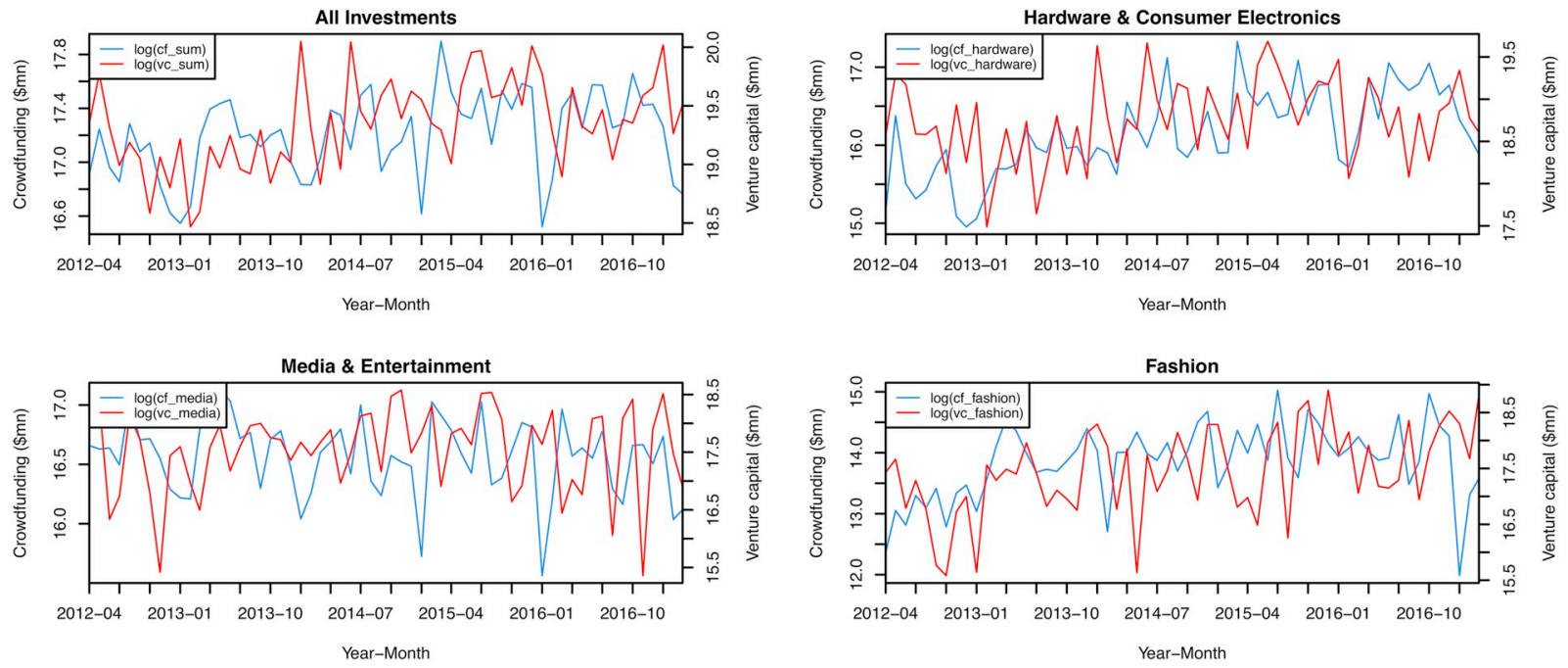

Fig. 1. Time series of monthly volumes of crowdfunding and venture capital investment.

augmented $\operatorname{VAR}\left(p+m_{\max }\right)$ in levels, where $p$ is the selected lag order and $m_{\max }$ is the highest order of integration suspected in the system (in our case, at most 1). A bivariate vector autoregressive model without deterministic terms can be formalized as

$$
\begin{aligned}
& \mathrm{X}_{t}=a_{1}+\sum_{i=1}^{p} \beta_{i} \mathrm{X}_{t-i}+\sum_{j=p+1}^{p+m_{\max }} \beta_{j} \mathrm{X}_{t-j}+\sum_{i=1}^{p} \gamma_{i} \mathrm{Y}_{t-i}+\sum_{j=p+1}^{p+m_{\max }} \gamma_{j} \mathrm{Y}_{t-j}+\varepsilon_{1 t} \\
& \mathrm{Y}_{t}=a_{2}+\sum_{i=1}^{p} \delta_{j} \mathrm{Y}_{t-i}+\sum_{j=p+1}^{p+m_{\max }} \delta_{j} \mathrm{Y}_{t-j}+\sum_{i=1}^{p} \varphi_{j} \mathrm{X}_{t-i}+\sum_{j=p+1}^{p+m_{\max }} \varphi_{j} \mathrm{X}_{t-j}+\varepsilon_{2 t}
\end{aligned}
$$

where $\beta, \gamma, \delta, \varphi$ are the parameters of the model, $\varepsilon_{1 t}$ and $\varepsilon_{2 t}$ are error terms and assumed to be white noise with zero mean, constant variance and no autocorrelation. In the first equation, the null hypothesis of noncausality from $Y$ to $X$ can be expressed as $H_{0}=\gamma_{j}=0, \forall i=1,2, \ldots p$. Thus, causality implies $\gamma_{j} \neq 0$.

To conduct the Toda-Yamamoto Granger causality test, we employ three sequential procedures:

1. We determine the maximum order of integration $m_{\max }$ for each pair of our variables. For our VAR models, we conclude that $m_{\max }=0$ or 1 .

2. We ensure the fit of our bivariate model through an appropriate lag length selection $m$, allowing for a drift in each series. We determine the optimal lag order to ascertain that the VAR is well-specified by minimizing one of the common information criteria: Akaike information criterion (AIC), Bayesian information criterion (BIC) or Schwartz information criterion (SIC) and final prediction error (FPE). We test for autoregressive conditional heteroskedasticity (ARCH) and we take care of the remaining serial correlation in the residuals through a Ljung and Box (1978) asymptotic portmanteau test. Subsequently, we check on the inverse roots of AR characteristics of polynomials for dynamic stability.

3. We test with $p+1$ and $p-1$ if the causality among different lags shows highly volatile or rather smooth transition patterns. We do so in order to control for potentially spurious causalities. In our analysis, we do not find a case where results for $p-1 / p+1$ lag order show reverse outcomes for causality.

\section{Results}

\subsection{Descriptive statistics}

Fig. 1 shows the development of our time series. The upper left graph depicts the development of the monthly volume of aggregate VC investments and crowdfunding during the sample period. The remaining graphs show monthly volumes of VC investments and crowdfunding in our three investment categories. The upper right graph visualizes the monthly volumes in the hardware category for $1380 \mathrm{VC}$ investments that sum to $\$ 9.28$ billion and for 9449 successful Kickstarter campaigns that raised $\$ 719.7$ million (see Table 2). The lower left graph depicts monthly investment volumes in the largest crowdfunding investment category, media. There are in sum $1044 \mathrm{VC}$ investments totaling $\$ 3.14$ billion, while 60,792 Kickstarter campaigns raised $\$ 983.9$ million. Lastly, the lower right graph depicts the time series for fashion. Over the course of the analysis horizon, we count 689 VC investments totaling $\$ 2.93$ billion, while at the same time, 3102 Kickstarter campaigns raised a total of $\$ 72.9$ million.

\subsection{Order of integration}

As evidenced by the ADP and PP test, most of our log-transformed time series appear to be stationary, allowing for a drift in each series. However, considering a significance level of $5 \%$ for the rejection of $\mathrm{H}_{0}$ for the existence of stationarity, the KPSS test does not allow for a clear conclusion on the potential presence of unit roots. We further examine whether differencing the time series provides more conclusive results towards stationarity, i.e. whether the time series are possibly I(1). The results of the ADF, PP and KPSS tests jointly conclude that the differenced log-transformed time series are stationary. Detailed results are in the Appendix (Table A.2).

Taken together, our results lack convincing evidence to reject the possibility of no unit root in the variables. The time series are either stationary at level $I(0)$ or weakly integrated at first order $I(1)\left(\mathrm{m}_{\max }=0\right.$ or 1), allowing for a drift. In the following bivariate VAR models, we will consider a maximum order of integration I(1) and model the extra augmented lag, as proposed by Toda and Yamamoto (1995), correspondingly $\left(m_{\max }=1\right)$. 
Table 2

Descriptive statistics at project level.

\begin{tabular}{|c|c|c|c|c|c|c|c|}
\hline Variable & Count & Volume (\$) & Mean (\$) & Std. dev. (\$) & $25 \%(\$)$ & $50 \%(\$)$ & $75 \%(\$)$ \\
\hline \multicolumn{8}{|c|}{ Investment segments and subsegments } \\
\hline cf_sum & 77,654 & $1,854,454,361$ & 23,881 & 170,988 & 2155 & 5421 & 14,289 \\
\hline vc_sum & 3260 & $16,109,421,248$ & $4,941,540$ & $9,257,321$ & 250,000 & $1,211,522$ & 5000,000 \\
\hline vc_angel_seed & 1557 & $1,166,521,982$ & 749,211 & 999,499 & 100,000 & 350,000 & $1,000,000$ \\
\hline vc_early_growth & 1703 & $14,942,899,266$ & $8,774,456$ & $11,506,675$ & $1,339,016$ & $4,211,000$ & $10,607,101$ \\
\hline \multicolumn{8}{|c|}{ Investment categories } \\
\hline cf_hardware & 9449 & $719,718,616$ & 76,168 & 386,112 & 4060 & 15,075 & 50,839 \\
\hline vc_hardware & 1380 & $9,279,699,936$ & $6,724,420$ & $10,850,992$ & 500,849 & $2,000,000$ & $7,500,000$ \\
\hline cf_media & 60,792 & $983,946,914$ & 16,186 & 114,772 & 2032 & 5000 & 10,940 \\
\hline vc_media & 1044 & $3,139,848,972$ & $3,007,518$ & $6,932,093$ & 120,000 & 666,728 & $2,300,400$ \\
\hline cf_fashion & 3102 & $72,932,129$ & 23,511 & 67,938 & 2446 & 7660 & 20,915 \\
\hline vc_fashion & 689 & $2,929,039,787$ & $4,251,146$ & $8,257,423$ & 240,000 & $1,000,000$ & $4,000,000$ \\
\hline
\end{tabular}

Table 3

Toda and Yamamoto (1995) modified Wald (MWald) test for granger causality.

\begin{tabular}{|c|c|c|c|c|}
\hline Pair & $\mathrm{Lag} / \mathrm{m}_{\max }$ & $\chi^{2}$ & p-Value & Granger causality \\
\hline \multicolumn{5}{|c|}{ Investment segments and subsegments } \\
\hline cf_sum $\nrightarrow$ vc_sum & $2(1)$ & 8.96 & $0.011^{* *}$ & Unidirectional causality \\
\hline vc_sum $\nrightarrow$ cf_sum & $2(1)$ & 1.06 & 0.588 & cf_sum $\rightarrow$ vc_sum \\
\hline cf_sum $\nrightarrow$ vc_early_growth & $2(1)$ & 8.95 & $0.011^{* *}$ & Unidirectional causality \\
\hline vc_early_growth $\nrightarrow$ cf_sum & $2(1)$ & 1.26 & 0.532 & cf_sum $\rightarrow$ vc_early_growth \\
\hline cf_sum $\nrightarrow$ vc_angel_seed & $1(1)$ & 0.54 & 0.464 & Unidirectional causality \\
\hline vc_angel_seed $\nrightarrow$ cf_sum & $1(1)$ & 8.49 & $0.004^{* * * *}$ & vc_angel_seed $\rightarrow$ cf_sum \\
\hline \multicolumn{5}{|l|}{ Investment categories } \\
\hline cf_hardware $\nrightarrow$ vc_hardware & $2(1)$ & 5.04 & $0.080^{*}$ & Unidirectional causality \\
\hline vc_hardware $\nrightarrow$ cf_hardware & $2(1)$ & 1.85 & 0.396 & cf_hardware $\rightarrow$ vc_hardware \\
\hline cf_media $\nrightarrow$ vc_media & $8(1)$ & 19.10 & $0.015^{* *}$ & Bidirectional causality \\
\hline vc_media $\nrightarrow$ cf_media & $8(1)$ & 22.10 & $0.005^{* * *}$ & (feedback) \\
\hline cf_fashion $\nrightarrow v c_{-}$fashion & $4(1)$ & 11.80 & $0.019^{* *}$ & Unidirectional causality \\
\hline vc_fashion $\nrightarrow$ cf_fashion & $4(1)$ & 1.60 & 0.808 & cf_fashion $\rightarrow$ vc_fashion \\
\hline
\end{tabular}

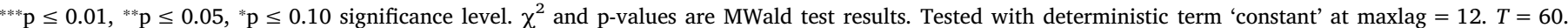

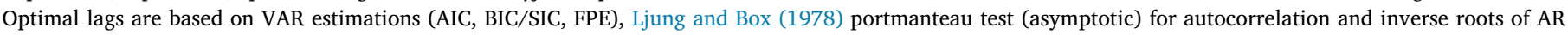

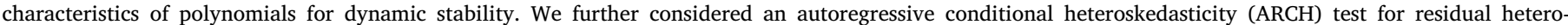

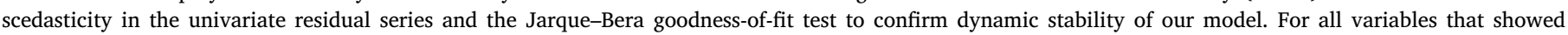
ambiguous order of integration, or seasonal effects, we repeated the tests, adjusted corresponding lags and can confirm robustness of the results.

\subsection{Granger causality (Toda and Yamamoto, 1995)}

In Table 3 , we report the $\chi^{2}$-test statistics and p-values obtained from the Toda-Yamamoto Granger causality MWald tests (against the null hypothesis of no Granger causality). The results indicate that there is a strong Granger causality running from cf_sum to vc_sum $\left(\chi^{2}=8.96\right.$, $\mathrm{p}=0.011)$. This causality is unidirectional, as we cannot reject the hypothesis of non-causality from vc_sum to $\mathrm{cf}_{-} \operatorname{sum}\left(\chi^{2}=1.06\right.$, $\mathrm{p}=0.588) .{ }^{12}$ The trend of this time series is highly influenced by the VC subsegment vc_early_growth that shows a strong unidirectional causality from crowdfunding towards venture capital $\left(\chi^{2}=8.95\right.$, $\mathrm{p}=0.011)$. Interestingly, vc_angel_seed shows a strong unidirectional causality in the other direction, i.e. towards improving the prediction of cf_sum $\left(\chi^{2}=8.49, \mathrm{p}=0.004\right)$. Thus, we find a complementary effect, such that the existence of angel and seed capital positively affects the level of crowdfunding activity.

\footnotetext{
${ }^{12}$ In view of lag order selection, we also consider other proposed lags for the VAR model and can confirm the stability of our overall results. Causalities in these tests are indicative of a rather robust model, whereas a less robust model would be expected to show less symmetric transitions or alternating bidirectional causalities. We therefore believe not to present the results of an instantaneous, or spurious causality (Granger, 1969).
}

For investment categories, the null hypothesis of non-causality running from cf_hardware to vc_hardware is also rejected $\left(\chi^{2}=5.04\right.$, $\mathrm{p}=0.080$ ), while non-causality in the other direction cannot be rejected $\left(\chi^{2}=1.85, \mathrm{p}=0.396\right)$. Further findings also indicate a bidirectional causality (feedback) between cf_media and vc_media $\left(\chi^{2}=19.10, p=0.015, \chi^{2}=22.10, p=0.005\right)$ and a unidirectional causality running from cf_fashion to vc_fashion $\left(\chi^{2}=11.80, \mathrm{p}=0.019\right.$, $\left.\chi^{2}=1.60, p=0.808\right)$. Altogether, the total of crowdfunding investments and in particular, crowdfunding in the hardware and media categories, Granger causes respective VC investments. Considering seasonal effects within the time series, we repeated the analysis with logtransformed and seasonally adjusted data. In this experiment, we find similar effects.

In order to inspect the dynamic effects of changes in crowdfunding on VC investments graphically, we apply an impulse response analysis. In Fig. 2, we consider the effects of a one standard deviation shock of cf_sum (positive deviation from the steady state) on vc_sum, and we look at the effects of a one standard deviation shock of cf_hardware on vc_hardware. The plots show a Cholesky decomposition for each bivariate VAR with optimal number of lags chosen under consideration of the BIC and FPE information criteria. For each figure, the solid line indicates the point estimate and dashed lines indicate the two-sided $90 \%$ bootstrapped confidence interval. As both variables are logtransformed, the y-axis in our figures represent percentage changes. 


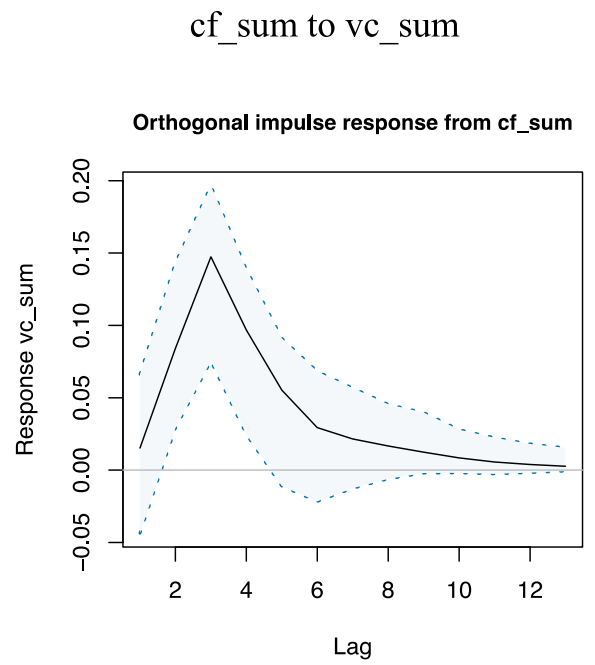

Orthogonal impulse response function of $\log$ vc_sum to a $1 \% \log$-increase in cf_sum.

cf_hardware to vc_hardware

Orthogonal impulse response from cf_hardware

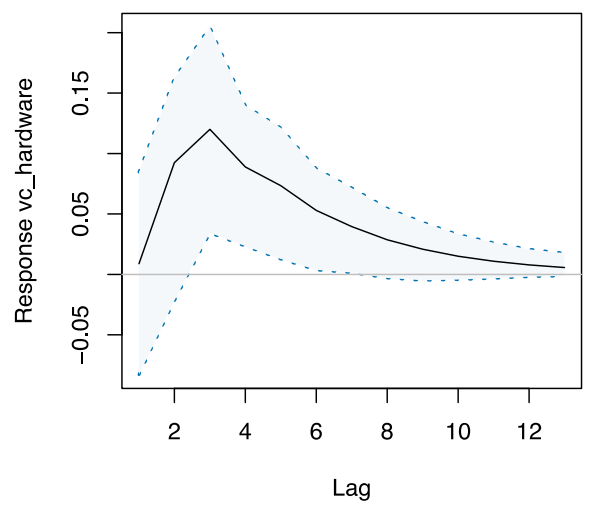

Orthogonal impulse response function of log vc_hardware to a $1 \% \log$-increase in cf_hardware. cf_sum to vc_sum (cumulative)

Cumulative impulse response from cf_sum

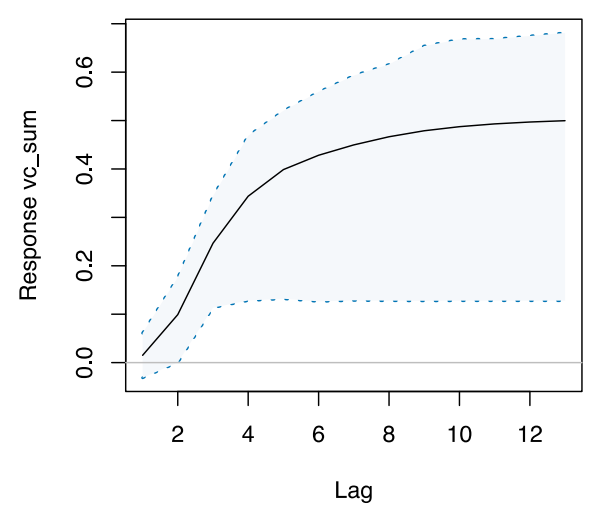

Cumulative impulse response function of $\log \mathrm{vc}$ sum to a $1 \% \log$-increase in cf_sum.

cf_hardware to vc_hardware (cumulative)

Cumulative impulse response from cf_hardware

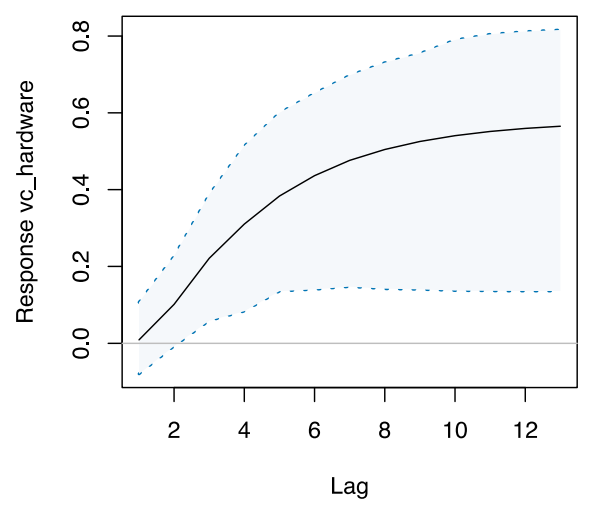

Cumulative impulse response function of $\log$ vc_hardware to a $1 \% \log$-increase in cf_hardware.

Fig. 2. Impulse response functions.

A $1 \% \log$-increase in total crowdfunding investments has an effect of a $14 \%$ increase in total VC investments at lag 3. Cumulatively, there is a positive effect on vc_sum until lag 6 (a total increase of about 40\%). Similarly, vc_hardware responds positively to a $1 \%$ log-increase in cf_hardware, with a response of $12 \%$ increase, peaking at lag 3 . Cumulatively, there is a persistent positive effect on vc_hardware until lag six (total increase of 42 percentage points). Overall, the impulse response analysis resonates well with the results from the Toda and Yamamoto (1995) Granger causality analyses, as well as the observable time series patterns in Fig. 1.

\subsection{Cointegration}

Under the assumption that our time series are $I(1)$ and integrated of the same order, the bivariate Johansen cointegration trace and max eigenvalue test indicate (at a $1 \%$ and $5 \%$ level) that there are cointegration relationships among our analyzed time series pairs (Table 4).
For cf_sum and vc_sum, we can reject the null hypothesis that there is no cointegration vector $(r=0)$ among the two time series. Similarly, we find at least one cointegration vector for both subsegments (angel_seed and early_growth) and all categories (hardware, media, fashion). ${ }^{13}$ As such, the results of cointegration relationships support our previous tests we showed in Table 3. For time series that are indicative for a causal relationship, the hypotheses of no cointegration relationship cannot be rejected at the $5 \%$ level.

\footnotetext{
${ }^{13}$ We further confirm these results by using the bounds testing approach developed by Pesaran et al. (2001), which is based on the OLS (ordinary least squares) estimation of an ARDL (Autoregressive Distributed Lag) equation. The model in the sense of Pesaran et al. (2001) is not only capable to work with both $I(0)$ and $I(1)$ variables (as found in the PP and KPSS test) but also more stable towards small sample sizes (Narayan, 2005; Pesaran et al., 2001).
} 
Table 4

Bivariate Johansen cointegration test.

\begin{tabular}{|c|c|c|c|c|c|c|}
\hline Variable & Lag & CIV & Eigenvalue & Trace statistic & $\begin{array}{l}\text { Max } \\
\text { Eigenvalue }\end{array}$ & Conclusion \\
\hline \multicolumn{7}{|c|}{ Investment segments and subsegments } \\
\hline \multirow[t]{2}{*}{ cf_sum, vc_sum } & 2 & $\mathrm{r} \leq 1$ & 0.136 & $8.51^{*}$ & $8.51^{*}$ & Cointegration relationship \\
\hline & & $\mathrm{r}=0$ & 0.389 & $37.10^{* * *}$ & $28.60^{* * *}$ & \\
\hline \multirow[t]{2}{*}{ cf_sum, vc_angel_seed } & 2 & $\mathrm{r} \leq 1$ & 0.138 & $8.60^{*}$ & $8.60^{*}$ & Cointegration relationship \\
\hline & & $\mathrm{r}=0$ & 0.370 & $35.40^{* * *}$ & $26.80^{* * *}$ & \\
\hline \multirow[t]{2}{*}{ cf_sum, vc_early_growth } & 2 & $r \leq 1$ & 0.145 & $9.12^{*}$ & $9.12^{*}$ & Cointegration relationship \\
\hline & & $\mathrm{r}=0$ & 0.392 & $38.00^{* * *}$ & $28.89^{* * *}$ & \\
\hline \multicolumn{7}{|l|}{ Investment categories } \\
\hline \multirow[t]{2}{*}{ cf_hardware, vc_hardware } & 2 & $r \leq 1$ & 0.119 & 7.33 & 7.33 & Cointegration relationship \\
\hline & & $\mathrm{r}=0$ & 0.328 & $30.40^{* * *}$ & $23.10^{* * *}$ & \\
\hline \multirow[t]{2}{*}{ cf_media, vc_media } & 8 & $r \leq 1$ & 0.094 & 5.13 & 5.13 & Cointegration relationship \\
\hline & & $\mathrm{r}=0$ & 0.263 & $21.00^{* * *}$ & $15.90^{* *}$ & \\
\hline \multirow[t]{2}{*}{ cf_fashion, vc_fashion } & 4 & $r \leq 1$ & 0.112 & 6.68 & 6.68 & Cointegration relationship \\
\hline & & $\mathrm{r}=0$ & 0.220 & $20.56^{* *}$ & $13.88^{*}$ & \\
\hline
\end{tabular}

${ }^{* * *} \mathrm{p} \leq 0.01,{ }^{* *} \mathrm{p} \leq 0.05,{ }^{*} \mathrm{p} \leq 0.10$ significance level. Tested with deterministic term 'constant' at maxlag $=12, T=60$. The respective null hypothesis is denoted as

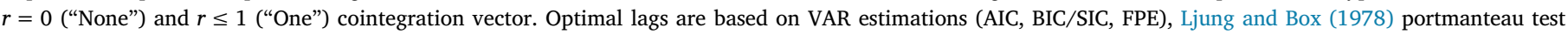

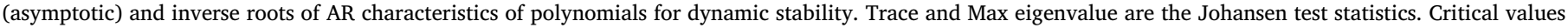

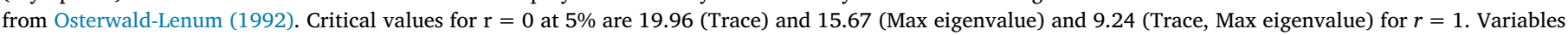
are log-transformed.

\subsection{Extensions and robustness checks}

\subsubsection{Crowding out}

We have extensively elaborated on the positive link between crowdfunding and VC. In a typical case, crowdfunding and VC are two different asset classes. They vary in terms of size, stage, scalability, investment duration and equity share as well as screening, monitoring, and advice. To some extent, crowdfunding investors might provide advice and support such as VC investors do. Crowdfunding investors know their needs and may possess knowledgeable skills in the technical domain in which the project operates. Via online communication, backers of projects often assist the entrepreneur in product development (Belleflamme et al., 2014; Frydrych et al., 2014). Moreover, entrepreneurs may prefer crowdfunding to VC because the crowd provides financial capital up-front and not conditional on reaching various milestones as it is common in VC financing (Tian, 2011; Tian and Wang, 2014). In some segments of the market, both types of investors are active and in these segments, entrepreneurs may thus substitute formal capital with informal capital from the crowd.

Therefore, in this section we consider the view that crowdfunding increases the supply of funds that compete for a limited number of projects. If this is the case, crowdfunding and VC investments could be substitutes and crowdfunding could crowd out VC investments. We focus on the segment of "small" VC investments.

To investigate whether crowding-out effect exists when projects involve smaller amounts of financing, we restrict our dataset in the following way. We include all successful crowdfunding investments with an initial fundraising goal larger than $\$ 100,000 .{ }^{14}$ By doing so, we assume projects that aim to raise (at least) $\$ 100,000$ might also have considered VC investments in a range $\$ 100,000$ upwards ("cf_sum_100k", $\mathrm{n}=822$ ). At the other end of the VC investment spectrum, we restrict our sample to investments larger than or equal to $\$ 100,000$ and smaller than or equal to $\$ 1,000,000$ ("vc_sum_100k", $\mathrm{n}=1118$ ). We show the descriptive statistics in Appendix Table A.3.

\footnotetext{
${ }^{14}$ Taking into account that about $23 \%(n=200)$ of Kickstarter projects with a fundraising goal of $\$ 100,000$ or more, effectively raised more than $\$ 500,000$ and 90 of them even more than $\$ 1,000,000$, we believe that such a range mirrors both, successful crowdfunding projects and appears potentially attractive for VC transactions. Hence, crowding out in this segment is more likely to occur.
}

Just like our previous time series, we log transform our data, ensure stability of our bivariate VAR model and then repeat the Toda and Yamamoto (1995) approach. Testing with a maximum order of integration $I(1)$, the test results (Appendix Table A.4) indicate a unidirectional causality running from cf_sum_100k to vc_sum_100k $(\chi 2=8.03)$ at $10 \%$ significance level, while results for causality running from vc_sum_100k to cf_sum_100k strongly support the null hypothesis of non-causality $(\chi 2=3.51, p=0.476)$. Again, a Johansen cointegration test also confirms previous findings from Granger causality, as we find one cointegration vector in the bivariate VAR system at a $1 \%$ significance level.

As employed previously, we complement the analysis with impulse response functions. Fig. 3 plots show a Cholesky decomposition for each bivariate VAR with optimal number of lags chosen with BIC and FPE information criteria. Despite a small positive response at lag 4, Fig. 3 shows a negative $15 \%$ response of vc_sum_100k to a $1 \%$ increase in cf_sum_100k, peaking at lag 5, which is weakly significant. The cumulative impulse response of vc_small remains negative at a level of about 30 percentage points, but is not statistically significant. These results indicate no conclusive evidence for crowding out effects.

\subsubsection{Variation across US states}

The relation between crowdfunding and VC may differ across different US states because they differ in cultural, institutional and economic environments, which have been cited as a mainstay for entrepreneurial activity. Cross-country evidence highlights how individuals are likely to display behavior in accordance with social norms and economic incentives around them (Stephan and Uhlaner, 2010). Hence, environmental factors could affect the supply of entrepreneurs especially within different states, which in turn can relate to the crowdfunding and VC activity. Crowdfunding has been generally attributed to broaden the scope of entrepreneurs by giving those in depleted areas access to financing even across states (Agrawal et al., 2015).

In fact, empirical evidence documents a robust relation between economic freedom and entrepreneurial activity, such that fewer frictions in the labor market are associated with more start-up activity (Cumming and Li, 2013). We re-estimate our Granger causality for those states that have an above median level of economic freedom and compare them to those that have a below median level of economic freedom to test for the robustness of the crowdfunding-VC relationship we reported. For this sample split, we employ the Index of Economic 
Orthogonal impulse response from cf_sum_100k

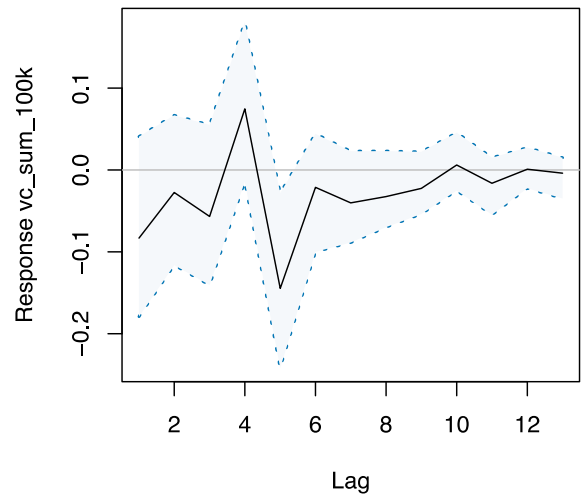

Cumulative impulse response from cf_sum_100k

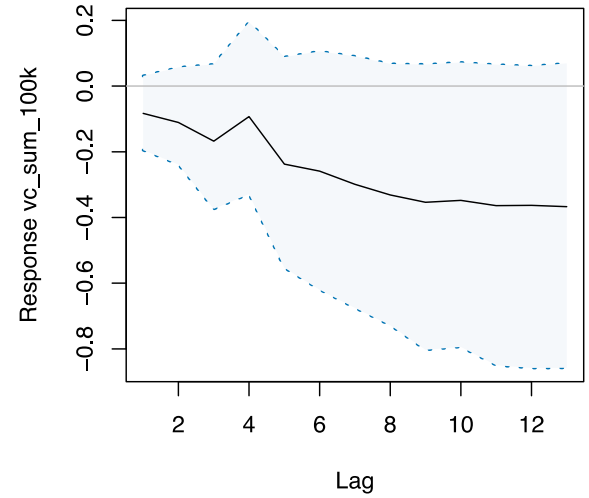

Orthogonal impulse response function of Cumulative impulse response function of vc_sum_100k vc_sum_100k to a $1 \% \log$-increase in cf_sum_100k. to a $1 \% \log$-increase in cf_sum_100k.

Fig. 3. Impulse response functions for crowdfunding "goal" $\geq \$ 100,000$, VC "usd_amount_raised" $\geq \$ 100,000 \leq \$ 1,000,000$.

Table 5

Toda and Yamamoto (1995) modified Wald (MWald) test for Granger causality.

\begin{tabular}{|c|c|c|c|c|}
\hline Pair & $\mathrm{Lag} / \mathrm{m}_{\max }$ & $\chi^{2}$ & p-Value & Granger causality \\
\hline \multicolumn{5}{|c|}{ Region } \\
\hline \multicolumn{5}{|c|}{ Economic freedom: below (M0) vs. above (M1) median } \\
\hline cf_sum_M0 $\nrightarrow$ vc_sum_M0 & $1(1)$ & 2.42 & 0.120 & \multirow{4}{*}{$\begin{array}{l}\text { Unidirectional causality } \\
\text { cf_sum_M1 } \rightarrow \text { vc_sum_M1 }\end{array}$} \\
\hline vc_sum_M0 $\nrightarrow$ cf_sum_M0 & $1(1)$ & 0.08 & 0.775 & \\
\hline cf_sum_M1 $\nrightarrow$ vc_sum_M1 & $3(1)$ & 11.20 & $0.011 * *$ & \\
\hline vc_sum_M1 $\nrightarrow$ cf_sum_M1 & $3(1)$ & 1.00 & 0.800 & \\
\hline \multicolumn{5}{|l|}{ California excluded } \\
\hline cf_sum_nCA $\nrightarrow$ vc_sum_nCA & $4(1)$ & 18.70 & $0.001 * * *$ & \multirow{2}{*}{$\begin{array}{l}\text { Unidirectional causality } \\
\text { cf_sum_nCA } \rightarrow \text { vc_sum_nCA }\end{array}$} \\
\hline vc_sum_nCA $\nrightarrow$ cf_sum_nCA & $4(1)$ & 2.22 & 0.696 & \\
\hline \multicolumn{5}{|c|}{ Other sources of entrepreneurial finance } \\
\hline cf_sum $\nrightarrow$ gvc & $2(1)$ & 0.39 & 0.820 & \multirow[t]{2}{*}{ No causality. } \\
\hline gvc $\nrightarrow$ cf_sum & $2(1)$ & 3.91 & 0.142 & \\
\hline cf_sum $\nrightarrow$ vlend & $2(1)$ & 0.95 & 0.621 & No causality. \\
\hline vlend $\nrightarrow$ cf_sum & $2(1)$ & 0.51 & 0.774 & \\
\hline
\end{tabular}

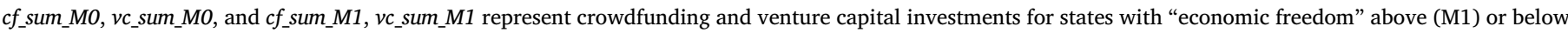

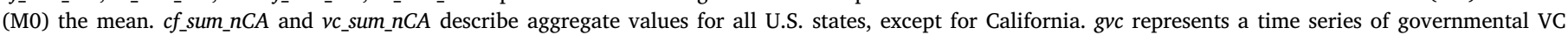

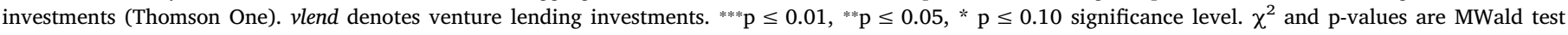

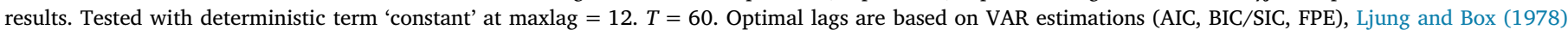

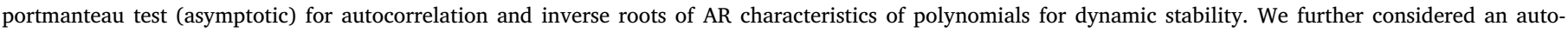

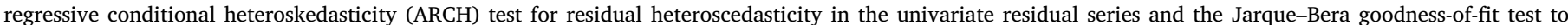

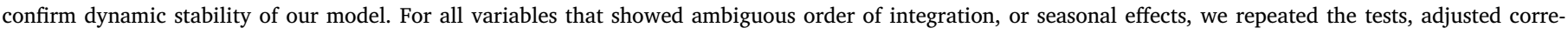
sponding lags and can confirm robustness of the results.

Freedom (composite measure comprising the three areas government spending, taxation, and labor market restrictions) provided by the Fraser Institute (https://www.fraserinstitute.org).

Our results in Table 5 show that the relation between crowdfunding and venture capital investments is directional and strong $\left(\chi^{2}=11.20\right.$, $\mathrm{p}=0.011$ ) among those states that report higher degrees of economic freedom but not for those that report lower degrees of economic freedom. Hence, we conclude that the results reported in the states which face lower levels of economic freedom are affected by a pertinent factor for a causal link between crowdfunding-VC investments such as a lower supply of high quality entrepreneurial ventures. We believe that this provides evidence on the conditionality of our findings on the supply of high potential start-ups to transition from crowdfunding to VC.

Subsequently, we check whether our results are driven by the state of California. Not only is California the state with the largest level of VC activities, it is also the state with the by far highest accelerator activity (Hochberg et al., 2017). As the surge in accelerator programs coincides with entrepreneurship (Cumming and Li, 2013), the high accelerator activity may influence the match between crowdfunding and VC financing. Following Cohen and Hochberg (2014) we obtain data on accelerator activities from Seed DB. California stands out with 2967 accelerated companies (from 29 programs). Among the other states, none really sticks out and only two other states report a number of accelerated companies in three digits (New York: 169; Ohio: 126). Our results in Table 5 show that the link between crowdfunding and venture capital is directional and robust outside California. Here, the null hypothesis of non-causality running from crowdfunding to venture capital is rejected $\left(\chi^{2}=18.70, p=0.001\right)$. Our main result is thus not driven by California.

\subsubsection{Other sources of entrepreneurial finance}

Our main analysis focusses on the aggregate of crowdfunding and VC investments. Yet, substantial heterogeneity may exist among the VC investment categories. In addition, other sources of entrepreneurial finance may be worth investigating. 
We tease out governmental VC investments (gvc), which are often thought to operate differently due to their different aims, focus and governance structure, by relying on recent work and data from Tykvová (2017). Hence, there may not necessarily a link between crowdfunding and gvc, as gvc is likely to be judged inferiorly by entrepreneurs (Cumming and MacIntosh, 2006). We employ data on monthly gvc investments from Thomson One. As the results in Table 5 show, for gvc we do not find a causal relation, which might in fact be due to the lack of attractiveness of these types of investments for entrepreneurs backed by crowdfunding.

Lastly, recent work points out the inter-connectedness of VC financing and venture lending, as a source of financing for young companies. Tykvová (2017) reports that entrepreneurial companies may in fact obtain both, venture lending and VC, while venture lending typically occurs in later stages than VC investments. While we are able to demonstrate that crowdfunding precedes future VC financing, our data set in the main part excludes venture lending explicitly. To assess the robustness of the relationship, we collect data on monthly venture lending volumes from Dow Jones Venture Source to test whether crowdfunding may influence future venture lending activities. Our results in Table 5 report no relationship between crowdfunding and venture lending (vlend). Given the typical late-stage focus of venture lending, this appears unsurprising. We believe that this analysis may require a longer-term analysis with more lags in the empirical estimation to be able to tease out potential effects.

\section{Summary of results and discussion}

Recently, researchers have started to investigate the link between crowdfunding and VC at the company level. These studies conclude that successful crowdfunding is positively related to future VC financing (Colombo and Shafi, 2016; Drover et al., 2017b; Kuppuswamy and Roth, 2016; Ryu and Kim, 2016). Other related work has already started to analyse the relation between crowdfunding and VC investments on a regional level (Sorenson et al., 2016). Notwithstanding the contribution of these related works, our analysis differs markedly along several dimensions. We focus on aggregate dollar amounts of Kickstarter investments as opposed to a binary dichotomization (number of successful projects). Our extension therefore accounts for the magnitude of investment activity. Frankly, there is much to be gained by conditioning on the amount raised, as there may be huge variations in Kickstarter campaigns as documented in prior work (Mollick, 2014).

We find that crowdfunding and VC investment volumes are related and we document a strong unidirectional Granger causality running from crowdfunding investments to VC. Results from a Toda-Yamamoto causality analysis are supported by a strong cointegration between the two respective time series, suggesting a long-run relationship between them. Our findings are consistent with the view that successful crowdfunding campaigns help new technologies to get attention from VC investors. The involvement of an online community may attest to the viability of a technology and provide an estimate of potential market size. This in turn, may influence the perception of other (later stage) investors positively. Our findings draw a picture of crowdfunding as being a faster and a more flexible investment vehicle than VC investments. Crowdfunding may rapidly adapt to changing economic conditions and to common wide shocks because the fundraising and the decision processes are less complex compared to VC funding (Kaplan and Strömberg, 2004; Mollick, 2013).

Our results are particularly strong in states with high levels of economic freedom. This corroborates findings in Sorenson et al. (2016) who show that crowdfunding might expand the geographic scope of VC investments by providing funding to areas in which VC financing has been absent, where yet a large of number start-ups reside. Our ancillary analyses enable a deeper reasoning with regard to confounding factors such as the financial and economic environment. The link we find in our study therefore strongly emphasizes the notion of entrepreneurial activity as a pre-requisite for the inter-relatedness of entrepreneurial financing eco-systems (Cumming et al., 2014).

The findings of this paper inform about the role crowdfunding plays in financing entrepreneurial ventures and they contribute to several strands of the literature. We add to the emerging literature on crowdfunding (e.g., Agrawal et al., 2015; Ahlers et al., 2015; Cumming and Johan, 2017; Mollick, 2013; Mollick and Kuppuswamy, 2014; Mollick and Nanda, 2015). We provide several analyses concerning potential confounding factors that were not included in prior work. More specifically, we analyse causality between categories by employing measures of governmental VC investments, venture lending, accelerator activities, and the Index of Economic Freedom.

The interplay between different types of entrepreneurial finance is a new and interesting research topic (Tykvová, 2018). Several works address the link between business angels and VC investors (Berkovitch et al., 2015; Chemmanur and Chen, 2014; Hellmann et al., 2015; Hellmann and Thiele, 2015). Angels differ from the universe of VC firms, as they follow a more informal (and geographically local) approach to deal selection. We contribute to this literature by studying crowding-out effects in angel and seed segment (along the lines of DeGennaro and Dwyer, 2014) and early and growth segment. Here we find that crowdfunding Granger causes VC investments in the early/ growth segment, but the causality goes in the other direction in the angel/seed segment. We also check whether in the segment of "small" VC and "large" crowdfunding investments, crowdfunding may crowdout VC financing. Here, we find only a negligible and mostly insignificant effect. Thus, crowdfunding helps early-stage and late-stage VC investors in assessing future trends rather than crowding them out of the market.

The Kickstarter platform has the appealing feature of comprising several sectors (which we summarized into three main investment categories) that are characterized by varying degrees of market potentials, scalability, and investment needs and may differ in the longevity of trends involved. We account more specifically for the characteristics of the Kickstarter initiated projects by analysing hardware, media and fashion related investments. In doing so, we also pay close attention to matching categories that are present in both types of investments (thus ruling out industries such as biotechnology and software, that are large in VC but have no corresponding category in Kickstarter). In addition, we break down the analysis into segments to see if causality trends hold.

Our results suggest that the crowd provides an accurate assessment of trends in industries that involve hardware and media, This corroborates prior findings, that in areas, such as gaming, internet-related technologies, wearable computing, and three-dimensional printing the crowd appears to be a reliable predictor (Mollick and Nanda, 2015). In addition, even in industries prone to short-lived trends and fads, such as fashion we find a causal link between crowdfunding and VC investments. We therefore think that our results are generalizable across industry boundaries and provide evidence on strong links between the various investment segments.

\section{Limitations and avenues for further research}

As with all research, this study is not without limitations. We concentrate on industries and investment types with sufficient levels of activity to make prudent estimates. This means that, for data reasons, we exclude some industries in which we might expect to find a strong link between early-stage crowdfunding and subsequent VC investments, such as biotechnology. We do not include this sector because we observe only a low number of biotechnology related investments on Kickstarter. Biotech startups and ventures in other very risky and capital-intensive industries rather obtain equity-based than reward-based crowdfunding investments. Several authors started to investigate the 
interplay between equity crowdfunded startups and venture capital (for instance, Ahlers et al., 2015; Agrawal et al., 2016; Hornuf et al., 2018). We focus on reward-based crowdfunding only and do not consider other types of crowdfunding. Equity-based crowdfunding shows too little comprehensive activity, which prohibits a Granger analysis as the results might suffer a bias because of months in which no or little activity occurs. Donation-based crowdfunding differs in the underlying economic exchange mechanism so that we would not expect a causal link to VC investments to exist. Yet, other types of crowdfunding deserve further research. While reward-based and equity-based crowdfunding share similarities in cues that investors are looking for, the two types of financing also exhibit several characteristics that may cause substitution effects in the long-run (Cholakova and Clarysse, 2015; Drover et al., 2017a). As such, we are only at the beginning of understanding the interplay between different types of early-stage financing sources (Hornuf and Schwienbacher, 2018a, 2018b). Given harmonized and public datasets for a longer period of analysis, we think it might be worthwhile to investigate the aggregate time-dependent relationship between reward-based and equity-based crowdfunding. Certainly, the beauty of equity crowdfunding lies in the ability to directly match difference sources of capital within the same firm, which Hornuf et al. (2018) nicely illustrate.

Also, our work abstracts from changes in the legal environment that took place, though our descriptive statistics report a momentous increase in crowdfunding transactions after the JOBS act enactment. While consumer protection might be important for reward-based crowdfunding, it might not matter for equity-based crowdfunding. Interestingly, recent work in Hornuf and Schwienbacher (2016) shows that too strong investor protection may even limit the chances of young firms to get access to financing, especially in the context of equity crowdfunding. In future research, it might be worthwhile to extend the results in here and to contrast reward-based and equity-based crowdfunding mechanisms for nascent firms.

Our study touches on crowding out effects. We consider the hypothesis that if the crowd democratizes access to capital it may adversely affect the investment opportunities for VC investors for smaller investments. Overall, Granger analysis and impulse response results jointly suggest a causal inference with small and mostly insignificant negative relationships between crowdfunding and venture capital. Thus, a small potential crowding out effects could exits. However, the research is yet at an early stage and need to be interpreted with caution. The described model could be extended with regard to data density (overlap between crowd and VC investments) and alternative modelling of seasonal effects in order to yield conclusions that are more definitive. Based on our results, we would expect the most significant crowding out effects in the hardware segment (given that these represent the most successful projects on Kickstarter).

We find heterogeneities across firm stages. While crowdfunding tends to predict early and growth investments, in the angel and seed segment the causality goes in the other direction. These results call for a deeper understanding of the interplay between different sources of entrepreneurial finance in the ecosystem. In part, these results may attest to the growing maturity of crowdfunding such that the industry is moving away from the exploratory stages to a focus on commercialization. More research along these lines might be needed to further illumine how crowdfunding has changed since its inception.

We also detect differences across US states. More specifically, the causal effect of crowdfunding on VC investments exists only in states with higher levels of economic freedom. A supply of high quality ventures is necessary for crowdfunding to expand its geographical reach. Yet, we would welcome more research on other institutional, cultural and economic factors that may affect the causal relationship depicted in this paper, especially cross-country analyses appear to be of interest here.

\section{Conclusion}

Over the past years, crowdfunding platforms, such as Kickstarter, have offered financing to several ground-breaking technologies. Pebble, Oculus VR, and Trace have not only garnered media attention, but also attracted seven-digit funding. Boudreau and Lakhani (2013) note that "crowds expand the capabilities of companies; they should be viewed as another tool for organizational problem solving." Moreover, successful crowdfunding implies market creation for products whose needs have not been satisfied yet. Essentially, crowdfunding pledges reflect the "wisdom of the crowd" in "screening new venture offerings and voting with their individual investment pledges for the best ones" (Bruton et al., 2015). As such, the crowd can also enable VC investors to "nowcast" (Choi and Varian, 2012) the creative economy, new products, markets and proofs of concept.

Crowdfunding may validate the authenticity of a firm and its technology. It reduces uncertainty over the feasibility and viability of new technologies on the part of external, later stage, financiers, such as VC investors. Hence, signals on technological feasibility and commercial viability through crowdfunding platforms are important for outsiders to attest to the quality of the underlying businesses (Chaney, 2018). Without the aggregation of signals, it is impossible to reliably attest to the quality of the product and technology characteristics, and especially to understand the potential of radical new innovation and technologies (Davies and Giovannetti, 2018; Plummer et al., 2016).

Thus, crowdfunding is not only about collecting money from the crowd, but also about crowdsourcing information on needs and demands in the market, as well as new market creation. In this light, crowdfunding investments and projects, both merely originating from households (von Hippel, 2017), also appear to be a macroeconomic indicator and allow nowcasting (Choi and Varian, 2012) of trends related to entrepreneurship and innovation.

We expect crowdfunding to become a new and unique market-proof tool that enables higher accuracy in predicting market demands. Organizations have begun to embed the concept of crowdsourcing into their innovation processes. Sony's "First Flight" program encourages workers and external partners to develop new product ideas and pitch potential business plans and models. "First Flight" allows testing the popularity of products concepts (Belitski and Herzig, 2018). Important factors (beyond financial capital) that drive entrepreneurial activity are a mindset of experimentation. As such, crowdfunding helps entrepreneurs and investors alike to reduce current and future demand uncertainty (Schwienbacher, 2015; Strausz, 2017).

Our results suggest that crowdfunding can be viewed as an "experimental laboratory" for innovation, through which VC investors obtain access to new technologies and trends. VC-funded startups might jump on a bandwagon of new trends discovered on crowdfunding platforms and commercialize these ideas with more financial resources that make it possible to scale faster. Where the crowd provides signals through aggregated investments, the VC market responds with a lag of three months with proportionally higher investments. The crowd and the VC investors seem to be synergistic and complementary members of the same ecosystem. Crowdfunding thus completes capital markets and widens the financing and investment opportunities. In the course of the "Venture Capital Revolution" (Gompers and Lerner, 2001) since 2011, crowdfunding has taken its own place as a means of early-stage financing. It emerged as a valid financial resource for "try-ups", i.e. product-focused projects that are just on their way to become a "startup".

An environment that facilitates experimentation (and tolerates failures) is the mainstay of a prospering economic ecosystem that generates innovations (Kerr et al., 2014b). Within such an environment, numerous new business ideas compete, but only a few single ventures will actually survive and bring their products to market. 
Experimentation with various business ideas is necessary to separate the good from the bad opportunities. The mentioning of a successful crowdfunding campaign in a product advertisement therefore provides valuable quality signals to consumers (Wehnert et al., 2018). To create radically novel products and services, entrepreneurs - who act in good faith on imagined new venture ideas - must have the chance to experiment with their ideas (Manso, 2011). In comparison with 'real-life' experimentation, in which the costs of failure and stigma might be high (Landier, 2005), the crowd may provide a low-cost alternative for experimentation (Mollick, 2014). As such, crowdfunding may give rise to new sources of entrepreneurial activity, for example, users innovating for their own may commercialize through crowdfunding platforms (Brem et al., 2018; Oo et al., 2018). Our study supports the view that crowds are not "mad" but rather "wise" (Mollick and Nanda, 2015). Hence, the existence of crowdfunding encourages entrepreneurs to engage in more experimentation, which subsequently broadens the market for VC investments. Experimenting with diverse business ideas results in more ideas coming to fruition, and has a longer-lasting effect on subsequent novel activity (Kornish and Ulrich, 2011; Østergaard et al., 2011) and technological progress (Kerr et al., 2014a).

\section{Acknowledgements}

We would like to thank Cesar A. Hidalgo, Cristian Jara-Figueroa, Dominik Hartmann, and Yves-Alexandre de Montjoye (MIT) for valuable comments on earlier versions of this paper. Also, we are grateful to Yasin Ozcan, NBER, Vincenzo Capizzi, Università del Piemonte Orientale and Douglas Cumming, York University Schulich School of Business, for discussions. Oleksandr Zastupailo provided great support in generating large parts of the dataset. We gratefully acknowledge access to Dow Jones Venture Source and Thomson One provided by the DALAHO, University of Hohenheim. We further like to thank CrunchBase for providing us with full data access for academic use. The authors would like to thank the German Federal Ministry of Education and Research for supporting this reseach through the project "InnoFinance" (01IO1702).

\section{Appendix A}

Table A. 1

Monthly development of crowdfunding campaign contributions.

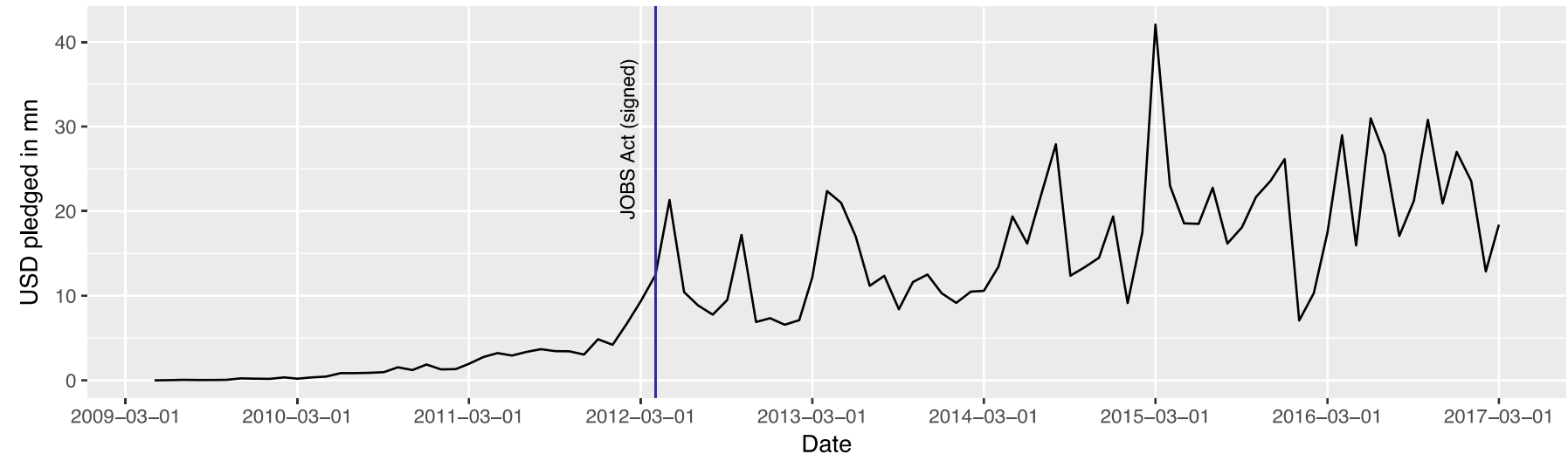

Table A.2

Unit-root tests.

\begin{tabular}{|c|c|c|c|c|c|c|}
\hline & $\mathrm{ADF} \mathrm{c}$ & $\mathrm{ADF}$ ct & PP c & PP ct & KPSS c & KPSS ct \\
\hline \multicolumn{7}{|l|}{ Variable } \\
\hline cf_sum & $-4.38^{* * *}$ & $-4.92^{* * * *}$ & $-4.60^{* * * *}$ & $-4.75^{* * * *}$ & $0.49^{* *}$ & 0.07 \\
\hline vc_sum & $-3.38^{* *}$ & $-4.58^{* * * *}$ & $-5.15^{* * *}$ & $-6.05^{* * *}$ & $0.74^{* * * *}$ & $0.13^{*}$ \\
\hline \multicolumn{7}{|l|}{ Categories } \\
\hline cf_hardware & $-2.74^{*}$ & $-4.55^{* * *}$ & $-4.02^{* * *}$ & $-5.52^{* * *}$ & $1.12^{* * * *}$ & 0.11 \\
\hline vc_hardware & $-4.12^{* * *}$ & $-4.52^{* * * *}$ & $-6.83^{* * *}$ & $-7.07^{* * *}$ & $0.43^{*}$ & $0.14^{*}$ \\
\hline cf_media & $-5.65^{* * * *}$ & $-5.92^{* * *}$ & $-6.18^{* * *}$ & $-6.38^{* * *}$ & 0.27 & 0.03 \\
\hline vc_media & $-7.58^{* * * *}$ & $-7.60^{* * *}$ & $-7.48^{* * *}$ & $-7.43^{* * *}$ & 0.18 & $0.18^{* *}$ \\
\hline cf_fashion & $-4.21^{* * *}$ & $-4.36^{* * * *}$ & $-5.38^{* * *}$ & $-5.60^{* * * *}$ & $0.61^{* *}$ & $0.23^{* * * *}$ \\
\hline vc_fashion & $-3.50^{* *}$ & $-4.97^{* * *}$ & $-5.92^{* * *}$ & $-7.21^{\text {**** }}$ & $0.75^{* * *}$ & 0.03 \\
\hline \multicolumn{7}{|l|}{ Segments } \\
\hline vc_early_growth & $-3.52^{* * *}$ & $-4.68^{* * * *}$ & $-5.29^{* * *}$ & $-6.10^{* * * *}$ & $0.70^{* *}$ & $0.12^{*}$ \\
\hline vc_angel_seed & $-3.20^{* *}$ & $-3.69^{* *}$ & $-5.46^{* * *}$ & $-6.32^{* * * *}$ & $0.79^{* * * *}$ & $0.28^{* * * *}$ \\
\hline gspend & $-5.95^{* * * *}$ & $-6.01^{* * *}$ & $-8.89^{* * *}$ & $-8.91^{* * *}$ & 0.19 & 0.09 \\
\hline vlend & $-5.24^{* * *}$ & $-6.33^{* * * *}$ & $-7.88^{* * *}$ & $-8.77^{* * * *}$ & $0.72^{* *}$ & 0.04 \\
\hline cf_sum_CA & $-4.50^{* * *}$ & $-4.78^{* * * *}$ & $-5.53^{* * *}$ & $-5.56^{* * * *}$ & 0.27 & 0.05 \\
\hline vc_sum_CA & $-4.84^{* * * *}$ & $-5.63^{* * *}$ & $-6.81^{* * *}$ & $-7.34^{* * * *}$ & $0.52^{* *}$ & $0.12^{*}$ \\
\hline cf_sum_nCA & $-4.52^{* * * *}$ & $-5.05^{* * *}$ & $-5.03^{* * *}$ & $-5.36^{* * * *}$ & $0.55^{* *}$ & 0.09 \\
\hline vc_sum_nCA & $-4.04^{* * *}$ & $-5.04^{* * * *}$ & $-5.77^{* * * *}$ & $-6.41^{* * * *}$ & $0.62^{* * *}$ & 0.08 \\
\hline cf_sum_M0 & $-4.41^{* * *}$ & $-4.74^{* * * *}$ & $-5.38^{* * *}$ & $-5.47^{* * *}$ & $0.36^{*}$ & 0.07 \\
\hline vc_sum_M0 & $-4.36^{* * * *}$ & $-5.22^{* * *}$ & $-6.06^{* * *}$ & $-6.53^{* * *}$ & $0.52^{* *}$ & $0.13^{*}$ \\
\hline cf_sum_M1 & $-4.43^{* * *}$ & $-5.05^{* * *}$ & $-5.53^{* * *}$ & $-5.95^{* * *}$ & $0.59^{* *}$ & 0.07 \\
\hline
\end{tabular}


Table A.2 (continued)

\begin{tabular}{|c|c|c|c|c|c|c|}
\hline \multicolumn{7}{|l|}{ Panel A: Level } \\
\hline & $\mathrm{ADF} \mathrm{c}$ & $\mathrm{ADF}$ ct & PP c & PP ct & KPSS c & KPSS ct \\
\hline vc_sum_M1 & $-3.74^{* * *}$ & $-4.54^{* * *}$ & $-6.49^{* * *}$ & $-7.21^{* * *}$ & $0.64^{* *}$ & 0.07 \\
\hline \multicolumn{7}{|c|}{ Panel B: First differences } \\
\hline & $\mathrm{ADF} \mathrm{c}$ & ADF ct & PP c & PP ct & KPSS c & KPSS ct \\
\hline \multicolumn{7}{|l|}{ Variable } \\
\hline cf_sum & $-8.16^{* * *}$ & $-8.14 * * *$ & $-9.80^{* * *}$ & $-9.73^{* * * *}$ & 0.09 & 0.04 \\
\hline vc_sum & $-8.52^{* * *}$ & $-8.46^{* * *}$ & $-15.07^{* * *}$ & $-14.99 * * *$ & 0.05 & 0.04 \\
\hline \multicolumn{7}{|l|}{ Categories } \\
\hline cf_hardware & $-9.05^{* * *}$ & $-9.02^{* * *}$ & $-12.30^{* * *}$ & $-12.18^{* * *}$ & 0.12 & 0.04 \\
\hline vc_hardware & $-8.98^{* * *}$ & $-8.92^{* * *}$ & $-18.71^{* * *}$ & $-18.57^{* * *}$ & 0.04 & 0.04 \\
\hline cf_media & $-8.30^{* * * *}$ & $-8.23^{* * *}$ & $-12.64^{* * *}$ & $-12.53^{* * *}$ & 0.04 & 0.04 \\
\hline vc_media & $-12.79^{* * *}$ & $-12.64^{* * *}$ & $-15.22^{* * *}$ & $-15.03^{* * *}$ & 0.05 & 0.05 \\
\hline cf_fashion & $-8.12^{* * *}$ & $-8.25^{* * *}$ & $-13.80^{* * *}$ & $-14.20^{* * *}$ & 0.15 & 0.04 \\
\hline vc_fashion & $-9.19^{* * *}$ & $-9.13^{* * *}$ & $-15.46^{* * *}$ & $-15.40^{* * *}$ & 0.06 & 0.04 \\
\hline \multicolumn{7}{|l|}{ Segments } \\
\hline vc_early_growth & $-8.46^{* * *}$ & $-8.40^{* * *}$ & $-14.86^{* * *}$ & $-14.80^{* * *}$ & 0.04 & 0.04 \\
\hline vc_angel_seed & $-8.15^{* * * *}$ & $-8.21^{* * * *}$ & $-18.26^{* * *}$ & $-18.30^{* * *}$ & 0.05 & 0.04 \\
\hline gspend & $-11.60^{* * * *}$ & $-11.48^{* * *}$ & $-19.19^{* * * *}$ & $-18.99^{* * *}$ & 0.03 & 0.03 \\
\hline vlend & $-11.45^{* * * *}$ & $-11.34^{* * *}$ & $-17.84^{* * *}$ & $-17.65^{* * *}$ & 0.06 & 0.04 \\
\hline cf_sum_CA & $-8.25^{* * * *}$ & $-8.21^{* * * *}$ & $-11.79^{* * *}$ & $-11.69^{* * *}$ & 0.07 & 0.04 \\
\hline vc_sum_CA & $-9.15^{* * *}$ & $-9.08^{* * *}$ & $-16.78^{* * *}$ & $-16.65^{* * *}$ & 0.05 & 0.04 \\
\hline cf_sum_nCA & $-9.06^{* * * *}$ & $-9.02^{* * *}$ & $-11.35^{* * * *}$ & $-11.32^{* * *}$ & 0.08 & 0.04 \\
\hline vc_sum_nCA & $-8.57^{* * *}$ & $-8.48^{* * *}$ & $-14.31^{* * *}$ & $-14.21^{* * *}$ & 0.03 & 0.03 \\
\hline cf_sum_M0 & $-7.75^{* * *}$ & $-7.72^{* * *}$ & $-11.55^{* * *}$ & $-11.47^{* * *}$ & 0.07 & 0.04 \\
\hline vc_sum_M0 & $-8.80^{* * *}$ & $-8.72^{* * *}$ & $-15.32^{* * *}$ & $-15.19^{* * *}$ & 0.05 & 0.05 \\
\hline cf_sum_M1 & $-7.95^{* * *}$ & $-7.91^{* * *}$ & $-13.15^{* * *}$ & $-13.08^{* * *}$ & 0.08 & 0.04 \\
\hline vc_sum_M1 & $-9.16^{* * * *}$ & $-9.09^{* * *}$ & $-16.55^{* * *}$ & $-16.43^{* * *}$ & 0.03 & 0.03 \\
\hline
\end{tabular}

Results report the ADF, PP and KPSS test results with deterministic terms constant (c) and constant and trend (ct). ADF $\mathrm{H}_{0}$ : Series has a unit root, $\mathrm{PP}_{\mathrm{O}}$ : Series has a unit root, KPSS $\mathrm{H}_{0}$ : Series is stationary. ADF critical values constant $(1,5,10 \mathrm{pct}):-3.51-2.89-2.58$. ADF critical values constant and trend $(1,5,10 \mathrm{pct}):-4.04-3.45-3.15$. Critical values are taken from Hamilton (1994) and Dickey and Fuller (1981). PP critical values constant $(1,5,10 \mathrm{pct}):-3.55,-2.91,-2.59$. PP critical values constant and trend $(1,5,10 \mathrm{pct}):-4.12,-3.49,-3.17$. Critical values are taken from MacKinnon (1991). KPSS critical values constant (1, 5, 10pct): 0.35, 0.46, 0.74, KPSS critical values constant and trend (1, 5, 10pct): $0.12,0.15,0.22$. Critical values are based on Kwiatkowski et al. (1992). ADF optimum lag length is estimated with the BIC. KPSS test maximum lag order (bandwidth) is chosen according to Schwert (1989). PP bandwith is estimated with Newey-West standard errors using a Bartlett window. Tested with a maximum lag $=12$ for 60 obs. ${ }^{* * *},{ }^{* *}, *$ denote 1,5 , and $10 \%$ significance level, respectively.

Table A.3

Descriptive statistics for crowdfunding campaigns with a goal $\geq \$ 100,000$ and venture capital investments $\geq \$ 100,000$ and $\leq \$ 1,000,000$.

\begin{tabular}{|c|c|c|c|c|c|c|c|}
\hline Variable & Count & Volume (\$) & Mean (\$) & Std. dev. (\$) & $25 \%(\$)$ & $50 \%(\$)$ & $75 \%(\$)$ \\
\hline cf_sum_100k & 822 & $441,893,446$ & 537,583 & $1,242,347$ & 131,373 & 208,545 & 469,525 \\
\hline vc_sum_100k & 1118 & $504,593,098$ & 451,336 & 301,815 & 185,000 & 388,112 & 679,522 \\
\hline
\end{tabular}

Table A.4

Toda and Yamamoto (1995) modified Wald (MWald) test for granger causality for crowdfunding campaigns with a goal $\geq \$ 100,000$ and venture capital investments $\geq \$ 100,000$ and $\leq \$ 1,000,000$.

\begin{tabular}{|c|c|c|c|c|}
\hline Pair & $\mathrm{Lag} / \mathrm{m}_{\max }$ & $\chi^{2}$ & $\mathrm{p}$-Value & Granger causality \\
\hline \multicolumn{5}{|l|}{ VAR } \\
\hline cf_sum $100 \mathrm{k} \nrightarrow \mathrm{vc} \_$sum_100k & $4(1)$ & 8.03 & $0.090^{*}$ & Unidirectional causality \\
\hline
\end{tabular}

${ }_{* * * *} \mathrm{p} \leq 0.01,{ }^{* *} \mathrm{p} \leq 0.05,{ }^{*} \mathrm{p} \leq 0.10$ significance level. $\chi^{2}$ and $\mathrm{p}$-values are MWald test results. Tested with deterministic term 'constant' at maxlag $=12$. $\mathrm{T}=60$. Optimal lags are based on VAR estimations (AIC, BIC/SIC, FPE), Ljung and Box (1978) portmanteau test (asymptotic) for autocorrelation and inverse roots of AR characteristics of polynomials for dynamic stability. We further considered an autoregressive conditional heteroskedasticity (ARCH) test for residual heteroscedasticity in the univariate residual series and the Jarque-Bera goodness-of-fit test to confirm dynamic stability of our model. For all variables that showed ambiguous order of integration, or seasonal effects, we repeated the tests, adjusted corresponding lags and can confirm robustness of the results. 


\section{References}

Agrawal, A., Catalini, C., Goldfarb, A., 2015. Crowdfunding: geography, social networks, and the timing of investment decisions. J. Econ. Manag. Strateg. 24 (2), 253-274.

Agrawal, A., Catalini, C., Goldfarb, A., 2016. Are syndicates the killer app of equity crowdfunding? Calif. Manag. Rev. 58 (2), 111-124.

Ahlers, G.K.C., Cumming, D., Günther, C., Schweizer, D., 2015. Signaling in equity crowdfunding. Enterp. Theory Pract. 39 (4) (955 880).

Alexy, O.T., Block, J.H., Sandner, P., Ter Wal, A.L., 2012. Social capital of venture capitalists and start-up funding. Small Bus. Econ. 39 (4), 835-851.

Åstebro, T., 2003. The return to independent invention: evidence of unrealistic optimism, risk seeking or skewness loving? Econ. J. 113 (484), 226-239.

Backus, D., 1986. The Canadian-US exchange rate: Evidence from a vector autoregression. Rev. Econ. Stat. 1, 628-637.

Belitski, M., Herzig, M., 2018. The jam session model for group creativity and innovative technology. J. Technol. Transf. 43 (2), 506-521.

Belleflamme, P., Lambert, T., Schwienbacher, A., 2014. Crowdfunding: tapping the right crowd. J. Bus. Ventur. 29 (5), 585-609.

Berkovitch, E., Grinstein, Y., Israel, R., January 25 2015. Entrepreneur Heterogeneity and New Venture Financing. (Available at SSRN: 2555205).

Block, J., Sandner, P., 2009. What is the effect of the financial crisis on venture capital financing? Empirical evidence from US internet start-ups. Ventur. Cap. 11 (4), 295-309.

Boudreau, K.J., Lakhani, K.R., 2013. Using the crowd as an innovation partner. Harv. Bus. Rev. 91 (4), 60-69.

Bradford, C.S., 2018. The regulation of crowdfunding in the United States. In: Cumming, D., Hornuf, L. (Eds.), The Economics of Crowdfunding. Palgrave Macmillan, Cham, pp. 185-217.

Brem, A., Bilgram, V., Marchuk, A., 2018. How crowdfunding platforms change the nature of user innovation-from problem solving to entrepreneurship. Technol. Forecast. Soc. Chang. https://doi.org/10.1016/j.techfore.2017.11.020. In press.

Bruton, G., Khavul, S., Siegel, D., Wright, M., 2015. New financial alternatives in seeding entrepreneurship: microfinance, crowdfunding, and peer-to-peer innovations. Enterp. Theory Pract. 39 (1), 926.

Budescu, D.V., Chen, E., 2014. Identifying expertise to extract the wisdom of crowds Manag. Sci. 61 (2), 267-280.

Chaney, D., 2018. A principal-agent perspective on consumer co-production: crowdfunding and the redefinition of consumer power. Technol. Forecast. Soc. Chang. https://doi.org/10.1016/j.techfore.2018.06.013. In press.

Chemla, G., Tinn, K., June 2016. Learning Through Crowdfunding. (Available at SSRN: 2804541).

Chemmanur, T.J., Chen, Z., 2014. Venture capitalists versus angels: the dynamics of private firm financing contracts. Rev. Corp. Finance Stud. 3 (1-2), 3986.

Cheng, Y., Huang, L., Ramlogan, R., Li, X., 2017. Forecasting of potential impacts of disruptive technology in promising technological areas: elaborating the SIRS epidemic model in RFID technology. Technol. Forecast. Soc. Chang. 117, 170183.

Choi, H., Varian, H., 2012. Predicting the present with Google trends. Econ. Rec. 88 (1), 2-9.

Cholakova, M., Clarysse, B., 2015. Does the possibility to make equity investments in crowdfunding projects crowd out reward-based investments? Enterp. Theory Pract. 39 (1), 145-172.

Cohen, S., Hochberg, Y.V., March 30, 2014. Accelerating Startups: The Seed Accelerator Phenomenon. (Available at SSRN: 2418000).

Colombo, M.G., Shafi, K., May 27, 2016. When Does Reward-Based Crowdfunding Help Firms Obtain External Financing? (Available at SSRN 2785538).

Cumming, D., Johan, S., 2017. Crowdfunding and entrepreneurial internationalization. In: The World Scientific Reference on Entrepreneurship: Volume 2: Entrepreneurial Finance-Managerial and Policy Implications, pp. 109-126.

Cumming, D., Li, D., 2013. Public policy, entrepreneurship, and venture capital in the United States. J. Corp. Finan. 23, 345-367.

Cumming, D.J., MacIntosh, J.G., 2006. Crowding out private equity: Canadian evidence. J. Bus. Ventur. 21 (5), 569-609.

Cumming, D., Johan, S., Zhang, M., 2014. The economic impact of entrepreneurship: comparing international datasets. Corp. Gov. 22 (2), 162-178.

Cumming, D.J., Leboeuf, G., Schwienbacher, A., May 31, 2015. Crowdfunding models: Keep-it-all vs. all-or-nothing. In: Working Paper, York University and University of Lille.

Cumming, D.J., Walz, U., Werth, J.C., 2016. Entrepreneurial spawning: experience, education, and exit. Financ. Rev. 51 (4), 507-525.

Cuthbertson, K., Hall, S.G., Taylor, M.P., 1992. Applied Econometric Techniques, Simon and Schuster. University of Michigan Press, Ann Arbor, MI.

Davidson, R., MacKinnon, J.G., 2004. Econometric Theory and Methods. Oxford University Press, New York.

Davies, W.E., Giovannetti, E., 2018. Signalling experience \& reciprocity to temper asymmetric information in crowdfunding evidence from 10,000 projects. Technol. Forecast. Soc. Chang. 133, 118-131.

Degennaro, R.P., Dwyer, G.P., 2014. Expected returns to stock investments by angel investors in groups. Eur. Financ. Manag. 20 (4), 739-755.

Dickey, D.A., Fuller, W.A., 1979. Distribution of the estimators for autoregressive time series with a unit root. J. Am. Stat. Assoc. 74 (366), 427431.

Dickey, D.A., Fuller, W.A., 1981. Likelihood ratio statistics for autoregressive time series with a unit root. Econometrica 1057, 1072.

Dolado, J.J., Lütkepohl, H., 1996. Making Wald tests work for cointegrated VAR systems. Econ. Rev. 15 (4), 369386.

Drover, W., Busenitz, L., Matusik, S., Townsend, D., Anglin, A., Dushnitsky, G., 2017a. A review and road map of entrepreneurial equity financing research: venture capital, corporate venture capital, angel investment, crowdfunding, and accelerators. J. Manag. 43 (6), 1820-1853.

Drover, W., Wood, M.S., Zacharakis, A., 2017b. Attributes of angel and crowdfunded investments as determinants of VC screening decisions. Enterp. Theory Pract. 41 (3), 323-347.

Engle, R.F., Granger, C.W., 1987. Cointegration and error correction: representation, estimation, and testing. Econometrica 251, 276.

Ewens, M., Rhodes-Kropf, M., 2015. Is a VC partnership greater than the sum of its partners? J. Financ. 70 (3), 1081-1113.

Frydrych, D., Bock, A.J., Kinder, T., Koeck, B., 2014. Exploring entrepreneurial legitimacy in reward-based crowdfunding. Ventur. Cap. 16 (3), 247-269.

Gamble, J.R., Brennan, M., McAdam, R., 2017. A rewarding experience? Exploring how crowdfunding is affecting music industry business models. J. Bus. Res. 70, 25-36.

Geweke, J., 1982. Measurement of linear dependence and feedback between multiple time series. J. Am. Stat. Assoc. 77 (378), 304-313.

Giles, D.E., 1997. Causality between the measured and underground economies in New Zealand. Appl. Econ. Lett. 4 (1), 63-67.

Gompers, P., Lerner, J., 2000. Money chasing deals? The impact of fund inflows on private equity valuation. J. Financ. Econ. 55 (2), 281-325.

Gompers, P., Lerner, J., 2001. The venture capital revolution. J. Econ. Perspect. 15 (2), $145-168$.

Granger, C.W., 1969. Investigating causal relations by econometric models and crossspectral methods. Econometrica 424, 438.

Granger, C.W., Newbold, P., 1974. Spurious regressions in econometrics. J. Econ. 2 (2), 111-120.

Hamilton, J.D., 1994. Time series analysis. 2. Princeton university press, Princeton, NJ, pp. 690-696.

Hellmann, T., Thiele, V., 2015. Friends or foes? The interrelationship between angel and venture capital markets. J. Financ. Econ. 115 (3), 639653.

Hellmann, T.F., Schure, P.H., Vo, D.H., May 2015. Angels and Venture Capitalists: Substitutes or Complements? (Available at SSRN: 2602739).

Hochberg, Y.V., Ljungqvist, A., Lu, Y., 2010. Networking as a barrier to entry and the competitive supply of venture capital. J. Financ. 65 (3), 829-859.

Hochberg, Y., Cohen, S., Fehder, D., 2017. Seed Accelerator Ranking. Available at. http://seedrankings.com/pdf/sarp_2017_accelerator_rankings.pdf.

Holtz-Eakin, D., Joulfaian, D., Rosen, H.S., 1994. Sticking it out: entrepreneurial survival and liquidity constraints. J. Polit. Econ. 102 (1), 53-75.

Hornuf, L., Schwienbacher, A., 2016. Should securities regulation promote equity crowdfunding? Small Bus. Econ. 49 (3), 1-15.

Hornuf, L., Schwienbacher, A., 2018a. Market mechanisms and funding dynamics in equity crowdfunding. J. Corp. Finan. 50, 556-574.

Hornuf, L., Schwienbacher, A., 2018b. Internet-based entrepreneurial finance: lessons from Germany. Calif. Manag. Rev. 60 (2), 150-175.

Hornuf, L., Schmitt, M., Stenzhorn, E., February 14 2018. Equity Crowdfunding in Germany and the UK: Follow-up Funding and Firm Failure. (Available at SSRN: 3020820).

Johansen, S., 1988. Statistical analysis of cointegration vectors. J. Econ. Dyn. Control. 12 (2), 231-254.

Johansen, S., Juselius, K., 1990. Maximum likelihood estimation and inference on cointegration with applications to the demand for money. Oxf. Bull. Econ. Stat. 52 (2), 169-210.

Kaplan, S.N., Strömberg, P., 2004. Characteristics, contracts and actions: evidence from venture capitalist analysis. J. Financ. 59 (5), 2177-2210.

Kerr, W.R., Lerner, J., Schoar, A., 2014a. The consequences of entrepreneurial finance: evidence from angel financings. Rev. Financ. Stud. 27 (1), 20-55.

Kerr, W.R., Nanda, R., Rhodes-Kropf, M., 2014b. Entrepreneurship as experimentation. J. Econ. Perspect. 28 (3), 25-48.

Kollmann, T., Kuckertz, A., 2010. Evaluation uncertainty of venture capitalists' investment criteria. J. Bus. Res. 63, 741-747.

Kornish, L.J., Ulrich, K.T., 2011. Opportunity spaces in innovation: empirical analysis of large samples of ideas. Manag. Sci. 57 (1), 107-128.

Kuppuswamy, V., Roth, K., May 2016. Research on the Current State of Crowdfunding: The Effect of Crowdfunding Performance and Outside Capital. Available at. https:// www.sba.gov/sites/default/files/433-Crowdfunding-Performance-and-OutsideCapital.pdf.

Kwiatkowski, D., Phillips, P.C., Schmidt, P., Shin, Y., 1992. Testing the null hypothesis of stationarity against the alternative of a unit root: how sure are we that economic time series have a unit root? J. Econ. 54 (1), 159-178.

Landier, A., November 2005. Entrepreneurship and the Stigma of Failure. (Available at SSRN: 850446).

Lehner, O.M., Grabmann, E., Ennsgraber, C., 2015. Entrepreneurial implications of crowdfunding as alternative funding source for innovations. Ventur. Cap. 17 (1-2), 171189.

Li, E., Martin, J.S., 2016. Capital formation and financial intermediation: the role of entrepreneur reputation formation. J. Corp. Finan. https://doi.org/10.1016/j. jcorpfin.2016.04.002. (In press).

Ljung, G.M., Box, G.E., 1978. On a measure of lack of fit in time series models. Biometrika 65 (2), 297-303.

Lütkepohl, H., 1990. Asymptotic distributions of impulse response functions and forecast error variance decompositions of vector autoregressive models. Rev. Econ. Stat. $116-125$.

Lütkepohl, H., Krätzig, M., 2004. Applied Time Series Econometrics. Cambridge University Press, Cambridge.

MacKinnon, J.G., 1991. Critical values for cointegration tests, Chapter 13 in Long-Run Economic Relationships: Readings in Cointegration. In: Engle, R.F., Granger, C.W.J. 
(Eds.), Oxford University Press, Oxford.

Maddala, G.S., Kim, I.M., 1998. Unit Roots, Cointegration, and Structural Change. Cambridge University Press, Cambridge.

Manso, G., 2011. Motivating innovation. J. Financ. 66 (5), 1823-1860.

Mollick, E.R., March 2013. Swept Away by the Crowd? Crowdfunding, Venture Capital, and the Selection of Entrepreneurs. (Available at SSRN: 2239204).

Mollick, E.R., 2014. The dynamics of crowdfunding: an exploratory study. J. Bus. Ventur. 29 (1), 1-16.

Mollick, E.R., July 2016. Containing Multitudes: The Many Impacts of Kickstarter Funding. (Available at SSRN: 2808000).

Mollick, E.R., Kuppuswamy, V., January 2014. After the campaign: outcomes of crowdfunding. In: UNC Kenan-Flagler Research Paper No. 2376997, (Available at SSRN: 2376997).

Mollick, E.R., Nanda, R., 2015. Wisdom or madness? Comparing crowds with expert evaluation in funding the arts. Manag. Sci. 62 (6), 1533-1553.

Narayan, P.K., 2005. The saving and investment nexus for China: evidence from cointegration tests. Appl. Econ. 37 (17), 1979-1990.

NVCA Venture Investment. available online. http://nvca.org/research/ventureinvestment/, Accessed date: 20 October 2017

Oo, P.P., Allison, T.H., Sahaym, A., Juasrikul, S., 2018. User entrepreneurs' multiple identities and crowdfunding performance: effects through product innovativeness, perceived passion, and need similarity. J. Bus. Ventur. https://doi.org/10.1016/j. jbusvent.2018.08.005. In press.

Østergaard, C.R., Timmermans, B., Kristinsson, K., 2011. Does a different view create something new? The effect of employee diversity on innovation. Res. Policy 40 (3), 500-509.

Osterwald-Lenum, M., 1992. A note with quantiles of the asymptotic distribution of the maximum likelihood cointegration rank test statistics. Oxf. Bull. Econ. Stat. 54 (3), 461-472.

Pesaran, M.H., Shin, Y., Smith, R.J., 2001. Bounds testing approaches to the analysis of level relationships. J. Appl. Econ. 16 (3), 289-326.

Phillips, P.C., 1986. Understanding spurious regressions in econometrics. J. Econ. 33 (3), 311-340.

Phillips, P.C., Perron, P., 1988. Testing for a unit root in time series regression. Biometrika 75 (2), 335-346.

Plummer, L.A., Allison, T.H., Connelly, B.L., 2016. Better together? Signaling interactions in new venture pursuit of initial external capital. Acad. Manag. J. 59 (5), 1585-1604.

Reynolds, P.D., 2011. Informal and early formal financial support in the business creation process: exploration with PSED II data set. J. Small Bus. Manag. 49 (1), 27-54.

Ryu, S., Kim, K., August 11 2016. Crowdfunding Success as a Quality Signal to Venture Capital. Available at. http://aisel.aisnet.org/cgi/viewcontent.cgi?article $=1369 \&$ context $=$ amcis 2016 .

Schwert, G.W., 1989. Tests for unit roots: A Monte Carlo investigation. J. Bus. Econ. Stat. 7, 147-159.

Schwienbacher, A., 2015. Entrepreneurial risk-taking in crowdfunding campaigns. Small Bus. Econ. 12, 1-17.

Schwienbacher, A., Larralde, B., 2012. Crowdfunding of small entrepreneurial ventures. In: Handbook of Entrepreneurial Finance. Oxford University Press, Oxford.

Sorenson, O., Assenova, V., Li, G.C., Boada, J., Fleming, L., 2016. Expand innovation finance via crowdfunding. Science 354 (6319), 1526-1528.

Stephan, U., Uhlaner, L.M., 2010. Performance-based vs socially supportive culture: a cross-national study of descriptive norms and entrepreneurship. J. Int. Bus. Stud. 41 (8), 1347-1364.

Strausz, R., 2017. A theory of crowdfunding: a mechanism design approach with demand uncertainty and moral hazard. Am. Econ. Rev. 107 (6), 1430-1476.

Tian, X., 2011. The causes and consequences of venture capital stage financing. J. Financ. Econ. 101 (1), 132-159.

Tian, X., Wang, T.Y., 2014. Tolerance for failure and corporate innovation. Rev. Financ. Stud. 27 (1), 211-255.

Toda, H.Y., Yamamoto, T., 1995. Statistical inference in vector autoregressions with possibly integrated processes. J. Econ. 66 (1), 225-250.

Tykvová, T., 2017. When and why do venture-capital-backed companies obtain venture lending? J. Financ. Quant. Anal. 52 (3), 1049-1080.

Tykvová, T., 2018. Venture capital and private equity financing: an overview of recent literature and an agenda for future research. J. Bus. Econ. 88 (3), 325-362.

Van Gelderen, M., Thurik, R., Bosma, N., 2006. Success and risk factors in the pre-startup phase. Small Bus. Econ. 26 (4), 319-335.

Von Frisch, K., 1967. The Dance Language and Orientation of Bees. Harvard University Press, Cambridge.

Von Hippel, E., 2017. Free Innovation. MIT Press, Cambridge.

Wehnert, P., Baccarella, C.V., Beckmann, M., 2018. In crowdfunding we trust? Investigating crowdfunding success as a signal for enhancing trust in sustainable product features. Technol. Forecast. Soc. Chang. https://doi.org/10.1016/j.techfore. 2018.06.036. In press.

Wiener, N., 1956. The theory of prediction. Mod. Math. Eng. 1, 125-139.

Zider, B.O.B., 1998. How venture capital works. Harv. Bus. Rev. 76 (6), 131-139.

Christian Hopp is a professor of technology entrepreneurship at RWTH Aachen.

His research encompasses various areas ranging from Venture Capital Financing, Human Resource Management, to Entrepreneurship. He has published in the Journal of Management Studies, Entrepreneurship Theory and Practice, Strategic Entrepreneurship Journal, among others.

Tereza Tykvova is Head of the Departement of Corporate Finance at the University of Hohenheim in Stuttgart. Prior to this appointment she has been a Senior researcher at the Dept. International Finance and Financial Management at ZEW Mannheim. Her work appeared in the Journal of Financial and Quantitative Analysis, Research Policy, the Journal of Banking and Finance, the Journal of Corporate Finance, among others.

Jermain Kaminski is a researcher at the Technology Entrepreneurship Group at RWTH Aachen. He studied economics at Witten/Herdecke University and was a visiting student and researcher at the Massachusetts Institute of Technology. Jermain likes to thank the Dr. Werner Jackstaedt Foundation for their exceptional support. 